\title{
Aspectos brioflorísticos e fitogeográficos de duas formações costeiras de Floresta Atlântica da Serra do Mar, Ubatuba/SP, Brasil
}

\author{
Nivea Dias dos Santos ${ }^{1,3}$, Denise Pinheiro da Costa ${ }^{2}$ Luiza Sumiko Kinoshita ${ }^{1} \&$ George John Shepherd \\ ${ }^{1}$ Departamento de Biologia Vegetal, Instituto de Biologia, \\ Universidade Estadual de Campinas - UNICAMP, CEP 13083-970, Campinas, SP, Brasil \\ ${ }^{2}$ Instituto de Pesquisas Jardim Botânico do Rio de Janeiro, \\ Rua Pacheco Leão 915, CEP 22460-030, Rio de Janeiro, RJ, Brasil \\ ${ }^{3}$ Autor para correspondência: Nivea Dias dos Santos, e-mail: nivea.dias@gmail.com
}

SANTOS, N.D., COSTA, D.P., KINOSHITA, L.S. \& SHEPHERD, G.J. Bryophytic and phytogeographical aspects of two types of forest of the Serra do Mar State Park, Ubatuba/SP, Brazil. Biota Neotrop. 11(2): http://www.biotaneotropica.org.br/v11n2/en/abstract?short-communication+bn03011022011

\begin{abstract}
Bryophytes are indicators of climatic, environmental and ecology conditions and are useful in the characterization of the vegetation types. In this study, we analyzed the brioflora of 2-ha plots, one of Restinga Forest (RF) and the other of Lowland Ombrophilous Dense Forest (LF), located in the Núcleo Picinguaba, State Park of Serra do Mar (São Paulo state, Brazil) aiming to: a) compare the structure of these communities; b) compare the floristic composition between these areas and with other coastal vegetations of southeastern Brazil; c) verify if the bryophytes of the Atlantic Forest lowlands have phytogeographic patterns wider than those of the montane species. In each plot, the bryophytes samples were collected at ten randomized subplots $(10 \times 10 \mathrm{~m})$. We found 152 species (87 liverworts, 64 mosses and one hornwort), of which 109 occur in RF (40 exclusives) and 112 in LF (43 exclusives). In terms of species richness and taxonomic diversity, LF was more diverse; however, the Simpson and Shannon index of diversity is higher in RF. The floristic composition, life form and ecological groups of light tolerance were significantly different between these two forests. Canopy opening (RF) and number of rocks (LF) were important environmental variables that influenced bryophyte distribution in the study areas. When evaluated in terms of landscape, the subplots of RF and LR form distinct floristic groups; however, at the regional level, the bryophytes of these two forest types have more similarities among themselves than with other Atlantic Forest areas. Bryophyte community observed in the Restinga Forest of Picinguaba shows more similarity with that of the neighbor Lowland Ombrophilous Dense Forest than with other Restinga or coastal formation, such as mangroves and caxetal. In both forests types studied, the majority of taxa $(>90 \%)$ is widely distributed in the world, presenting phytogeographic pattern equal to or wider than the Neotropical. Our results corroborate the idea that the RF of Picinguaba is a unique vegetation formation, presenting elements of ombrophilous and dryer forests. In addition, they reinforce the idea that, for the tropical bryophyte species, the phytogeographic patterns are wider in areas of lower altitudes.
\end{abstract}

Keywords: bryophytes, Restinga Forest, community structure, phytogeographic patterns, southeastern Brazil.

SANTOS, N.D., COSTA, D.P., KINOSHITA, L.S. \& SHEPHERD, G.J. Aspectos brioflorísticos e fitogeográficos de duas formações costeiras de Floresta Atlântica da Serra do Mar, Ubatuba/SP, Brasil. Biota Neotrop. 11(2): http://www.biotaneotropica.org.br/v11n2/pt/abstract?short-communication+bn03011022011

Resumo: Briófitas são bioindicadoras de condições climáticas, ambientais e ecológicas, sendo úteis na caracterização de tipos vegetacionais. Neste trabalho, foi analisada a brioflora de duas áreas de 1 ha, uma de Floresta de Restinga (FR) e outra de Floresta Ombrófila Densa de Terras Baixas (TB) do Núcleo Picinguaba, PE Serra do Mar (São Paulo, Brasil), com o objetivo de: a) comparar a estrutura dessas comunidades; b) entender as relações florísticas dessas áreas entre si e com outras formações litorâneas brasileiras; c) verificar se as briófitas de áreas de baixada apresentam padrões fitogeográficos mais amplos do que aquelas de áreas montanas. As briófitas foram coletadas em 10 subparcelas $(10 \times 10 \mathrm{~m})$ distribuídas aleatoriamente em cada fitofisionomia. Variáveis ambientais foram quantificadas e correlacionadas com a distribuição da brioflora. Foram registradas 152 espécies (87 hepáticas, 64 musgos e 1 antócero), das quais 109 ocorrem na FR (40 exclusivas) e 112 em TB (43 exclusivas). Em termos de riqueza de espécies e diversidade taxonômica, TB foi mais diversa; contudo, os índices de diversidade de Simpson e Shannon foram maiores na FR. A composição florística, tipos de forma de vida e grupos ecológicos de tolerância à luz apresentaram diferenças significativas entre as duas fitofisionomias. A abertura do dossel (FR) e rochosidade (TB) são variáveis ambientais importantes que atuam sobre a distribuição das briófitas nas áreas estudadas. Quando avaliadas em termos de paisagem, as subparcelas da FR e TB formaram grupos florísticos distintos; entretanto, em nível regional, a brioflora dessas duas fitofisionomias apresenta mais afinidades entre si do que com outras áreas de Floresta Atlântica. Em termos florísticos, a FR de Picinguaba assemelha-se mais às Florestas Ombrófilas do que a outras Restingas ou outras formações costeiras (como mangue e caxetal). Nas duas fitofisionomias, a maioria dos táxons (>90\%) é amplamente distribuída no mundo, 
Santos, N.D. et al.

apresentando padrão fitogeográfico igual ou maior do que o Neotropical. Nossos resultados corroboram a idéia de que a FR de Picinguaba é uma formação ímpar, apresentando em sua brioflora elementos de florestas ombrófilas entremeados àqueles de vegetações mais secas; além disso, reforçam a idéia de que, para as espécies de briófitas, os padrões fitogeográficos são mais amplos em locais de menores altitudes.

Palavras-chave: briófitas, Floresta de Restinga, estrutura de comunidades, padrões fitogeográficos, sudeste do Brasil.

\section{Introdução}

Briófitas é um termo artificial muito utilizado para o conjunto de três distintas linhagens de plantas criptógamas avasculares (musgos, hepáticas e antóceros), pertencentes ao subreino Embryophyta, e que atualmente estão agrupadas nas divisões Bryophyta, Marchantiophyta e Anthocerotophyta (Goffinet \& Shaw 2009). Constituem o grupo mais diverso de plantas sem flores, com 15.000-18.000 espécies no mundo, das quais 1.521 ocorrem no Brasil (Costa 2010), o que corresponde a ca. $10 \%$ da brioflora global e $38 \%$ daquela ocorrente na região Neotropical (Gradstein et al. 2001). Representam um componente característico das florestas tropicais úmidas, ocorrendo em microambientes muito específicos, como base de troncos de árvores, troncos de arbustos, troncos em decomposição, folhas e rochas (Pócs 1982). No Brasil, as florestas Amazônica e Atlântica constituem as regiões fitogeográficas de maior riqueza desse grupo vegetal. Contudo, quando comparadas, a Floresta Atlântica destacase em termos de diversidade e endemismo, devido principalmente à sua amplitude altitudinal e latitudinal (Gradstein \& Costa 2003), sendo reconhecidas 1.230 espécies (Costa 2009), das quais 353 (29\%) ocorrem no litoral norte do Estado de São Paulo (Visnadi 2005).

As briófitas são organismos sensíveis às condições ambientais, visto que não apresentam cutícula e, por isso, realizam trocas gasosas e de nutrientes por todo o gametófito, revelando-se boas bioindicadoras de condições climáticas, ambientais e ecológicas (Frahm \& Gradstein 1991, Hallingbäck \& Hodgetts 2000, Gradstein et al. 2001, Zartman 2003). Estudos recentes têm apontado essas plantas como indicadoras das fitofisionomias da Floresta Atlântica no sudeste do Brasil. Costa \& Lima (2005) e Santos \& Costa (2010a) verificaram que as floras de musgos e hepáticas se diferenciam ao longo do gradiente altitudinal, com táxons exclusivos de cada fitofisionomia. N.D. Santos et al. (dados não publicados) constataram que a similaridade da flora de hepáticas do Estado do Rio de Janeiro está mais relacionada ao tipo de fitofisionomia do que à proximidade geográfica das áreas analisadas. Com relação aos padrões fitogeográficos dos táxons, Santos \& Costa (2010b) destacaram que as florestas de terras baixas e submontanas são caracterizadas por espécies de hepáticas amplamente distribuídas, enquanto que nas florestas montanas e alto-montanas destacam-se espécies endêmicas e aquelas disjuntas com os Andes.

Tendo em vista o potencial indicador das briófitas e a necessidade de compreender se a Floresta de Restinga de Picinguaba (Ubatuba), litoral norte de São Paulo, constitui uma variação da Floresta Ombrófila Densa de Veloso et al. (1991) ou representa uma formação vegetacional ímpar, foi realizado o estudo das comunidades de briófitas de duas áreas de Floresta Atlântica do Parque Estadual da Serra do Mar. Os objetivos do trabalho foram: (1) num contexto de paisagem, comparar os dados de riqueza de espécies, diversidade, composição florística, formas de vida e grupos ecológicos da brioflora da Floresta de Restinga e de Terras Baixas de Picinguaba; (2) numa escala regional, analisar as afinidades florísticas entre as duas áreas e outras formações litorâneas brasileiras (Caxetal, Floresta Ombrófila Densa, Mangue e Restinga); e (3) em termos globais, verificar se as briófitas das florestas de altitudes mais baixas apresentam padrões fitogeográficos mais amplos do que aquelas das florestas montanas e alto-montanas do sudeste brasileiro, como observado por Santos $\&$ Costa (2010b).

\section{Material e Métodos}

\section{1. Área de estudo}

O estudo foi realizado no Núcleo Picinguaba do Parque Estadual da Serra do Mar (23 $31^{\prime}$ a $23^{\circ} 34^{\prime}$ S e $45^{\circ} 02^{\prime}$ a $\left.45^{\circ} 05^{\prime} \mathrm{O}\right)$, litoral norte do Estado de São Paulo. Foram realizadas coletas em duas parcelas de 1 ha, uma localizada na Floresta de Restinga (parcela A) e outra na Floresta Ombrófila Densa de Terras Baixas (parcela B). Para uma descrição detalhada das áreas de estudo, veja Joly et al. (2011).

\section{Amostragem e estudo do material}

Em cada parcela, as amostras de briófitas foram coletadas em 10 subparcelas $(10 \times 10 \mathrm{~m})$ distribuídas aleatoriamente, durante o período compreendido entre janeiro e setembro de 2009. A numeração das subparcelas está de acordo com aquela estabelecida pelo Projeto Gradiente Funcional (Joly \& Martinelli 2004). A metodologia de coleta, herborização e preservação do material segue Yano (1984). A identificação foi realizada principalmente com base na seguinte literatura: Bastos \& Yano (2006), Buck (1998), Costa (2008), Dauphin (2003), Gradstein \& Costa (2003), Gradstein et al. (2001), Heinrichs et al. (1988; 2000), Peralta (2005), Reese (1993), ReinerDrehwald (2000), Reiner-Drehwald \& Goda (2000), Vaz \& Costa (2006a; b) e Vaz-Imbassahy et al. (2008).

A classificação adotada é a proposta por Crandall-Stotler et al. (2009) para a Divisão Marchantiophyta, por Goffinet et al. (2009) para a Divisão Bryophyta e por Renzaglia et al. (2009) para a Divisão Anthocerotophyta. Todos os exemplares coletados estão depositados no herbário da Universidade Estadual de Campinas (UEC) com duplicatas no herbário do Instituto de Pesquisas Jardim Botânico do Rio de Janeiro (RB).

\section{Dados ambientais}

Para cada subparcela, as seguintes variáveis ambientais foram quantificadas: abertura do dossel, distância de córregos, número de lianas e cobertura da área por rochas e troncos em decomposição. Para o cálculo da abertura do dossel, foram tomadas fotografias hemisféricas a $1,3 \mathrm{~m}$ de altura do solo no centro de cada subparcela, tendo sido utilizadas câmeras digitais Nikon Coolpix 950 e 5000 equipadas com conversores "fish-eye" FC E8 Nikon. O cálculo da percentagem de abertura de dossel a partir das fotografias hemisféricas foi realizado no programa Gap Light Analyser (Frazer et al. 1999). A distância da subparcela a córregos foi medida a partir do centro da subparcela, tendo sido utilizadas as seguintes classes: $0=$ dentro de córrego, $1=1-10 \mathrm{~m}, 2=11-20 \mathrm{~m}$, $3=21-30 \mathrm{~m}, 4=>30 \mathrm{~m}$. As lianas foram quantificadas através das seguintes classes: $0=$ nenhuma liana, $1=1-5$ lianas, $2=6$ - 10 lianas, $3=11-20$ lianas, $4=>20$ lianas. Foram quantificadas todas as lianas que estavam na supbarcela, mesmo que seu ponto de enraizamento fosse fora desta. A cobertura da subparcela por rochas (rochosidade) e troncos em decomposição foi quantificada através das classes de Fournier (1974). Neste método os valores são obtidos em campo através de uma escala intervalar semi-quantitativa de cinco categorias ( 0 a 4 ) e intervalo de $25 \%$ entre cada categoria. 


\section{Análise dos dados}

Para cada fitofisionomia, foram analisadas as seguintes características da brioflora: riqueza de espécies, composição florística, diversidade, tipos de forma de vida, grupos ecológicos de tolerância à luz e padrões fitogeográficos dos táxons. Os índices de diversidade de espécies de Shannon (H') e Simpson (1-D) foram calculados no programa Past 1.92 (Hammer et al. 2001). Foi realizada também a conversão dos índices de diversidade em número efetivo de espécies, como proposto por Jost (2006); onde o número efetivo é a diversidade de espécies esperada caso todas as espécies de uma comunidade sejam igualmente comuns. Outro índice de diversidade utilizado foi a diversidade taxonômica, calculada no programa Past 1.92 (Hammer et al. 2001), sendo os intervalos de confiança estimados por meio de aleatorizações. O índice de diversidade taxonômica (ou filogenética) é uma extensão do índice de Simpson, que captura, além da estrutura da distribuição das abundâncias, a distância filogenética entre as espécies de uma comunidade (Magurran 2004). Ele baseia-se em distâncias topológicas, sendo estimado pelo número esperado de nós entre quaisquer dois indivíduos sorteados em uma comunidade (Warwick \& Clarke 1995, Clarke \& Warwick 1998).

A classificação das formas de vida segue a de Mägdefrau (1982), com modificações feitas por Richards (1984). Em relação às formas de vida pendentes, dois tipos foram reconhecidos: pendente (eixo principal pendente com base aderida ao substrato e eixos secundários curtos e horizontais) e flabelado (eixos com ramos num mesmo plano, projetados horizontal a obliquamente para baixo, com filídios aplanados). Foi realizada também uma distinção da forma de vida tapete taloso, compreendendo as hepáticas talosas (que não apresentam diferenciação entre filídios e caulídios). Quanto à tolerância à luz do sol, as briófitas foram classificadas em: generalistas, típicas de sol e típicas de sombra, baseando-se em dados da literatura (Gradstein et al. 2001, Gradstein \& Costa 2003, Alvarenga et al. 2010, Silva \& Pôrto 2010), em experiência de campo e na consulta a especialistas. Para analisar a relação entre a riqueza de espécies típicas de sol e o índice de abertura do dossel, foi realizada uma Regressão Linear Simples no programa BioEstat 5.0 (Ayres et al. 2007). Para testar as diferenças entre cada tipo de forma de vida e grupo ecológico de tolerância à luz da FR e TB ( $=10$ subparcelas em cada área), foi realizado o Teste de Mann-Whitney, que é um teste não-paramétrico usado para a comparação de dois grupos independentes. Essa análise foi feita no programa BioEstat 5.0 (Ayres et al. 2007). Os padrões fitogeográficos foram caracterizados a partir da sobreposição das extensões de ocorrência dos táxons, tendo sido adaptados a partir daqueles já descritos na literatura (Cabrera \& Willink 1980, Gradstein \& Costa 2003). O padrão fitogeográfico Amplo refere-se ao táxon que ocorre em mais de três continentes, incluindo áreas extratropicais.

A similaridade florística (índice de Sørensen) entre as duas fitofisionomias foi calculada com base nos dados de incidência (presença/ausência) das espécies de briófitas nas 20 subparcelas; sendo utilizado, posteriormente, o método de agrupamento de Média de Grupo (UPGMA). Nesta análise optou-se pela utilização do índice de Sørensen, pois ele exclui a dupla ausência e atribui peso dobrado à co-ocorrência (Valentin 2000). Para avaliar as correlações entre os gradientes ambientais e florísticos, foi realizada uma Análise de Correspondência Canônica (Canonical Correspondence Analysis CCA). Para tanto, os dados foram organizados em duas matrizes: uma contendo os dados de incidência das espécies nas subparcelas e outra com os dados das variáveis ambientais transformados (ranging). Para avaliar a significância dos primeiros eixos da ordenação, empregou-se o teste de Monte Carlo (Ter Braak \& Prentice 1988), com 99 permutações. Todas essas análises foram realizadas no programa Fitopac 2.0 (Shepherd 2009).

$\mathrm{Na}$ escala regional, para a análise das afinidades florísticas das fitofisionomias inventariadas com outros tipos vegetacionais da Floresta Atlântica litorânea do Brasil, foi confeccionada uma matriz que consistiu de dados binários para 343 espécies de briófitas (descritores) de 15 áreas (amostras), listadas na Tabela 1. Contudo, para aumentar a eficiência da análise de agrupamento, as espécies

Tabela 1. Lista das áreas de Floresta Atlântica costeira incluídas na análise das afinidades florísticas em nível regional. Siglas: EE = Estação Ecológica; FOD = Floresta Ombrófila Densa; N = número total de espécies utilizadas na matriz florística (excluindo sinônimos e táxons duvidosos); PARNA = Parque Nacional; PE = Parque Estadual; RPPN = Reserva Particular do Patrimômio Natural.

Table 1. List of areas of coastal Atlantic Forest included in the analysis of the floristic affinities regionally. Abbreviations: ES = Ecological Station; FOD = rainforest, $\mathrm{N}=$ total number of species in the floristic matrix (excluding doubtful taxa and synonyms); PARNA = National Park; SP = State Park; RPPN = Private Natural Heritage Reserve.

\begin{tabular}{ccccc}
\hline Fitofisionomia & Área/Estado & Sigla & N & Referência \\
\hline Caxetal & Ubatuba, SP & CxUbatuba & 104 & Visnadi (2009) \\
Floresta de Restinga & PE Serra do Mar, Ubatuba, SP & FloReUbatuba & 109 & Este trabalho \\
Floresta de Restinga & EE de Juréia, Peruíbe, SP & FloReJuréia & 41 & Vital \& Visnadi (1994) \\
FOD Terras Baixas & PE Serra do Mar, Ubatuba, SP & TBUbatuba & 112 & Este trabalho \\
FOD Terras Baixas & REBIO Poço das Antas, Miguel Pereira, RJ & TBPoço das Antas & 67 & Costa (1999) \\
FOD Submontana & RPPN El Nagual, Magé, RJ & SMElNagual & 133 & Santos \& Costa (2008) \\
Mangue & Ubatuba, SP & MnUbatuba & 73 & Visnadi (2008) \\
Restinga & PE Setiba, Guarapari, ES & RSetiba & 37 & Behar et al. (1992) e \\
& & & Visnadi \& Vital (1995) \\
Restinga & PARNA Jurubatiba, Quissamã & RJurubatiba & 41 & Imbassahy et al. (2009) \\
Restinga & e Carapebús, RJ & RMassambaba & 17 & Costa et al. (2006) \\
Restinga & Massambaba, RJ & RMacaé & 37 & Costa et al. (2006) \\
Restinga & PARNA Jurubatiba, Macaé, RJ & RRio das Ostras & 12 & Costa et al. (2006) \\
Restinga & Rio das Ostras, RJ & RMaricá & 11 & Costa et al. (2006) \\
Restinga & Maricá, RJ & RBahia & 27 & Bastos (1999) \\
Restinga & Salvador e litoral norte, BA & RJuréia & 22 & Vital \& Visnadi (1994) \\
\hline
\end{tabular}


raras (que ocorriam em apenas uma amostra) foram eliminadas. Dessa forma, a matriz final consistiu de dados de presença/ausência para 180 espécies de briófitas. Essa matriz foi submetida à análise de outliers com nível de corte 2 no programa PCOrd 4.1 (McCune \& Mefford 1999). A similaridade entre as áreas foi calculada através do coeficiente de Jaccard, tendo sido utilizado o método de agrupamento de Média de Grupo (UPGMA) no programa Fitopac 2.0 (Shepherd 2009). Foi utilizado o índice de similaridade de Jaccard, que dá peso igual para todas as espécies, para minimizar possíveis problemas de diferenças no esforço amostral dos levantamentos.

\section{Resultados}

\section{Brioflora das florestas de Restinga e Terras Baixas}

Foram identificadas um total de 38 famílias, 90 gêneros e 152 espécies de briófitas ( 87 hepáticas, 64 musgos e um antócero, Tabela 2), das quais 109 (61 hepáticas e 48 musgos) ocorrem na Floresta de Restinga (FR) e 112 (66 hepáticas, 45 musgos e um antócero) na Floresta Ombrófila Densa de Terras Baixas (TB). Apenas 69 espécies (45\%) são compartilhadas entre as duas fitofisionomias, 40 foram encontradas exclusivamente na FR e 43 em TB. Em termos de abundância (frequência) de espécies, 11 táxons (10\%) ocorreram em todas as subparcelas da FR e $10(9 \%)$ em todas de TB (Tabela 2). Dentre estas espécies, apenas duas (Isopterygium tenerum e Octoblepharum albidum) ocorreram em todas as 20 subparcelas inventariadas.

As principais famílias da FR foram Lejeuneaceae (38 espécies), Calymperaceae (sete) e Plagiochilaceae (sete), Brachytheciaceae (seis) e Lepidoziaceae (seis). Em TB destacaram-se Lejeuneaceae (37), Pilotrichaceae (nove), Plagiochilaceae (sete) e Neckeraceae (seis). Sete famílias foram encontradas apenas na FR (Lembophyllaceae, Myriniaceae, Orthotrichaceae, Phyllogoniaceae, Pottiaceae, Pterobryaceae e Rhizogoniaceae) e 10 apenas na TB (Bryaceae, Cephaloziaceae, Daltoniaceae, Dendrocerotaceae, Hypopterygiaceae, Monocleaceae, Pallaviciniaceae, Porellaceae, Racopilaceae e Thuidiaceae). Os gêneros mais ricos em ambas as fitofisionomias foram Lejeunea e Plagiochila (sete espécies cada), na FR destacam-se ainda: Syrrhopodon (cinco espécies), Cheilolejeunea (quatro), Bazzania, Ceratolejeunea, Leucobryum, Metzgeria, Sematophyllum e Squamidium (três espécies cada); já em TB, Ceratolejeunea e Syrrhopodon (quatro espécies cada), Frullania, Metzgeria, Radula e Sematophyllum (três espécies cada).

Os índices de diversidade de Simpson e Shannon foram semelhantes nas duas fitofisionomias (Tabela 3), sendo ligeiramente maiores na FR do que em TB. Ao converter esses índices de diversidade em número efetivo de espécies, a FR também obteve a maior diversidade (71 táxons, pelo índice de Simpson e 85 pelo de Shannon). O índice de diversidade taxonômica foi maior em TB do que na FR, apesar da diferença não ser significativa (Tabela 3).

A principal forma de vida observada nas duas fitofisionomias foi tapete, com 63 espécies (56\%) em TB e 58 espécies (53\%) na FR. As formas flabelada (14 espécies), tufo (11) e tapete taloso (oito) destacam-se ainda em TB; enquanto que tufo (17 espécies), flabelada (12) e pendente (nove) na FR (Tabela 2). Quando os dados de forma de vida das espécies das 10 subparcelas de cada fitofisionomia foram analisados separadamente, verificou-se que apenas as formas tapete e flabelada não apresentam variações estatisticamente significativas entre as fitofisionomias (Figura 1).

Com relação aos grupos ecológicos de tolerância à luz, na FR houve um predomínio de espécies generalistas (53 táxons - 49\%), seguidas das típicas de sombra (38 táxons) e de sol (18). Na floresta de TB a maioria das espécies é típica de sombra (52 táxons - 46\%), 46 são generalistas e 14 típicas de sol. Existem diferenças significativas entre a proporção de espécies típicas de sombra e típicas de sol entre a FR e TB (Figura 2). Além disso, a regressão realizada entre a riqueza de espécies típicas de sol e o índice de abertura do dossel foi significativa e demonstrou que a abertura do dossel explica $44 \%$ da variação da riqueza dessas espécies nas duas fitofisionomias estudadas $\left(\mathrm{R}^{2}=0,44 ; \mathrm{p}<0,001\right)$.

\section{Afinidades florísticas em nível de paisagem}

A análise de similaridade entre as 20 subparcelas inventariadas demonstrou pouca afinidade florística entre as amostras da FR e de TB. Apenas três subparcelas de TB tiveram similaridade maior do que 50\% com as da FR (B82 com A45, A89, A85 e A81; B98 com A45 e A81; e B34 com A81). O índice de Sørensen variou de 0,1 (entre as subparcelas A01 e B74) a 0,69 (entre A89 e A81). A análise de agrupamento (correlação cofenética 0,79 ) revelou a existência de dois grupos bem definidos, um formado pelas amostras da FR e outro pelas de TB (Figura 3). Esses mesmos grupos foram encontrados na análise de Correspondência Canônica (CCA), onde as amostras da FR formam um grupo coeso, influenciado principalmente pela maior abertura do dossel (Figura 4). Já as amostras de TB formam um gradiente desde aquelas áreas mais próximas a córregos, onde o índice de rochosidade é elevado até aquelas aonde há um elevado número de lianas. Os autovalores (AV) obtidos na análise para os três primeiros eixos de ordenação foram 0,$36 ; 0,17$ e 0,12 ; sendo responsáveis, respectivamente, por 14,7; 21,6 e 26,5\% da variância total acumulada dos dados. As porcentagens de variância acumulada nos três primeiros eixos foram menores do que aquelas esperadas pelo modelo broken stick (AV1 esperado 43,2; AV2 63,4 e AV3 77,8\%); dessa forma, os resultados explicam parcialmente a variação existente. A baixa variância explicada pelo primeiro eixo canônico da análise $(14,7 \%)$ pode estar relacionada ao fato deste eixo explicar apenas a parte linear do gradiente, enquanto que a curva esteve associada com o eixo não canônico (representando 8,5\% da variância). Portanto, a variância total associada ao gradiente foi de $23,2 \%$. As variáveis ambientais mais fortemente correlacionadas com o primeiro eixo de espécies foram abertura do dossel $(-0,92)$, rochosidade $(0,88)$, e distância de córrego $(-0,74)$; e com o segundo eixo, a distância de córregos $(0,64)$ e número de lianas $(0,54)$. O resultado do teste de Monte Carlo foi significativo para os dois primeiros eixos da ordenação (AV1 p = 0,01; AV2 p = 0,02).

\section{Afinidades florísticas em nível regional}

Não foram encontrados outliers dentre as áreas incluídas na análise das relações florísticas; dessa forma, todas as análises foram realizadas com as 15 áreas. Na análise de similaridade, foi verificado que as duas fitofisionomias amostradas em Picinguaba (município de Ubatuba) possuem baixa afinidade florística com as demais áreas, apresentando o maior índice de similaridade entre si (FR e TB de Ubatuba $=0,57)$. A FR de Ubatuba assemelha-se ainda à floresta submontana da RPPN El Nagual $(0,38)$ e ao Caxetal de Ubatuba $(0,37)$, tendo a menor similaridade com a Restinga de Rio das Ostras $(0,04)$. O resultado da análise de agrupamento (correlação cofenética 0,87 ) pode ser observado na Figura 5, onde foram formados dois grupos, um deles abrangendo todas as restingas analisadas, com exceção daquelas do Estado de São Paulo, e outro compreendendo as florestas ombrófilas do sudeste brasileiro e as formações litorâneas paulistas. Neste grupo, foi verificada a separação de três subgrupos: um, abrangendo as formações de Juréia (Floresta e Floresta de Restinga), localizadas em Peruíbe, litoral sul do Estado de São Paulo; outro, com duas formações litorâneas de Ubatuba (Mangue e Caxetal); e o terceiro, abrangendo as florestas ombrófilas (dentro do qual se encontra a FR de Ubatuba). Com este último grupo, a floresta 
Tabela 2. Lista das espécies de briófitas da Floresta de Restinga (FR) e da Floresta de Terras Baixas (TB) do PE da Serra do Mar, Ubatuba, SP, com dados sobre grupo ecológico de tolerância à luz, forma de vida e padrão fitogeográfico. Grupo ecológico (GE): gen = generalista, sol = típica de sol, som = típica de sombra. Forma de vida (FV): $\mathrm{DN}=$ dendróide, $\mathrm{P}=$ pendente, $\mathrm{F}=$ flabelado, $\mathrm{TF}=$ tufo, $\mathrm{TL}=$ talosa, $\mathrm{TP}=$ tapete, $\mathrm{TR}=$ trama.

Table 2. List of bryophytes species of the Restinga Forest (FR) and the Lowland Forest (TB) of PE Serra do Mar, Ubatuba, SP, with data about ecological group of light tolerance, life form and phytogeographical pattern. Ecological group $(\mathrm{GE})$ : gen = generalist, sol = sun plants, som = shade plant. Life form $(\mathrm{FV})$ : $\mathrm{DN}=$ dendroid, $\mathrm{P}=$ pending, $\mathrm{F}=$ flabellate, $\mathrm{T}=$ tuff, $\mathrm{TL}=$ thallose $\mathrm{TP}=$ mat, $\mathrm{TR}=$ weft.

\begin{tabular}{|c|c|c|c|c|c|c|}
\hline Família & Espécie & FR & TB & GE & FV & Padrão fitogeográfico \\
\hline \multicolumn{7}{|c|}{ Divisão Anthocerotophyta } \\
\hline Dendrocerotaceae & Megaceros vincentianus (Lehm. \& Lindenb.) Campb. & 0 & 5 & som & $\mathrm{TL}$ & Neotropical \\
\hline \multicolumn{7}{|l|}{ Divisão Bryophyta } \\
\hline \multirow[t]{6}{*}{ Brachytheciaceae } & Aerolindigia capillacea (Hornsch.) M. Menzel & 1 & 0 & som & $\mathrm{P}$ & Pantropical \\
\hline & Meteoridium remotifolium (Müll. Hal.) Manuel & 5 & 2 & gen & $\mathrm{P}$ & Neotropical \\
\hline & Squamidium brasiliense Broth. & 3 & 0 & som & $\mathrm{P}$ & Afroamericano \\
\hline & Squamidium isocladum (Renauld \& Cardot) Broth. & 1 & 0 & som & $\mathrm{P}$ & Neotropical \\
\hline & Squamidium nigricans (Hook.) Broth. & 1 & 1 & som & $\mathrm{P}$ & Neotropical \\
\hline & Zelometeorium patulum (Hedw.) Manuel & 8 & 8 & gen & $\mathrm{P}$ & Neotropical \\
\hline Bryaceae & Rhodobryum beyrichianum (Hornsch.) Müll. Hal. & 0 & 4 & som & $\mathrm{TF}$ & Amplo \\
\hline \multirow[t]{8}{*}{ Calymperaceae } & Calymperes erosum Müll. Hal. & 0 & 3 & som & $\mathrm{TF}$ & Pantropical \\
\hline & Calymperes palisotii Schwägr. & 1 & 0 & gen & $\mathrm{TF}$ & Amplo \\
\hline & Calymperes tenerum Müll. Hal. & 2 & 0 & som & $\mathrm{TF}$ & Pantropical \\
\hline & Syrrhopodon gardneri (Hook.) Schwägr. & 6 & 2 & som & $\mathrm{TF}$ & Pantropical \\
\hline & Syrrhopodon gaudichaudii Mont. & 2 & 0 & som & $\mathrm{TF}$ & Pantropical \\
\hline & Syrrhopodon incompletus Schwägr. & 10 & 6 & som & $\mathrm{TF}$ & Afroamericano \\
\hline & Syrrhopodon ligulatus Mont. & 1 & 2 & som & $\mathrm{TF}$ & $\begin{array}{c}\text { América tropical e } \\
\text { subtropical }\end{array}$ \\
\hline & Syrrhopodon prolifer Schwägr. & 9 & 4 & gen & $\mathrm{TF}$ & Pantropical \\
\hline Daltoniaceae & Leskeodon aristatus (Geh. \& Hampe) Broth. & 0 & 1 & som & $\mathrm{F}$ & Floresta Atlântica \\
\hline \multirow[t]{4}{*}{ Dicranaceae } & Holomitrium crispulum Mitt. & 4 & 0 & sol & $\mathrm{TF}$ & Neotropical \\
\hline & Leucoloma serrulatum Brid. & 5 & 2 & sol & $\mathrm{TF}$ & Neotropical \\
\hline & Octoblepharum albidum Hedw. & 10 & 10 & gen & $\mathrm{TF}$ & Neotropical \\
\hline & Octoblepharum pulvinatum (Dozy \& Molk.) Mitt. & 5 & 1 & gen & $\mathrm{TF}$ & Neotropical \\
\hline Fissidentaceae & Fissidens zollingeri Mont. & 2 & 10 & gen & $\mathrm{F}$ & Pantropical \\
\hline Hookeriaceae & Hookeria acutifolia Hook. \& Grev. & 2 & 1 & som & $\mathrm{TP}$ & Amplo \\
\hline \multirow[t]{2}{*}{ Hypnaceae } & Ectropothecium leptochaeton (Schwägr.) W.R. Buck & 0 & 2 & gen & $\mathrm{TP}$ & Neotropical \\
\hline & Vesicularia vesicularis (Schwägr.) Broth. & 4 & 10 & gen & $\mathrm{TP}$ & Neotropical \\
\hline Hypopterygiaceae & Hypopterygium tamarisci (Sw.) Brid. & 0 & 3 & som & $\mathrm{D}$ & Amplo \\
\hline Lembophyllaceae & Pilotrichella flexilis (Hedw.) Äongstr. & 3 & 0 & gen & $\mathrm{P}$ & Afroamericano \\
\hline \multirow[t]{4}{*}{ Leucobryaceae } & Leucobryum clavatum Hampe & 5 & 0 & gen & $\mathrm{TF}$ & Brasil \\
\hline & Leucobryum crispum Müll. Hal. & 1 & 1 & gen & $\mathrm{TF}$ & Neotropical \\
\hline & Leucobryum martianum (Hornsch.) Hampe ex Müll. Hal. & 1 & 0 & gen & $\mathrm{TF}$ & Neotropical \\
\hline & Ochrobryum gardneri (Müll. Hal.) Lindenb. & 8 & 10 & gen & $\mathrm{TF}$ & Afroamericano \\
\hline \multirow[t]{2}{*}{ Meteoriaceae } & Floribundaria flaccida (Mitt.) Broth. & 0 & 2 & som & $\mathrm{P}$ & Neotropical \\
\hline & Meteorium nigrescens (Hedw.) Dozy \& Molk. & 3 & 0 & som & $\mathrm{P}$ & $\begin{array}{l}\text { América tropical e } \\
\text { subtropical }\end{array}$ \\
\hline Myriniaceae & Helicodontium capillare (Hedw.) A.Jaeger & 2 & 0 & sol & TR & Neotropical \\
\hline \multirow[t]{7}{*}{ Neckeraceae } & Homalia glabella (Hedw.) Bruch \& Schimp. & 1 & 0 & som & $\mathrm{F}$ & Neotropical \\
\hline & Homaliodendron piniforme (Brid.) Enroth & 0 & 3 & som & $\mathrm{D}$ & Neotropical \\
\hline & Neckeropsis disticha (Hedw.) Kindb. & 8 & 10 & gen & $\mathrm{F}$ & Pantropical \\
\hline & Neckeropsis undulata (Hedw.) Reichardt & 8 & 8 & gen & $\mathrm{F}$ & Neotropical \\
\hline & Pinnatella minuta (Mitt.) Broth. & 0 & 1 & som & $\mathrm{D}$ & Afroamericano \\
\hline & Porothichum substriatum (Hampe) Mitt. & 6 & 10 & som & $\mathrm{D}$ & Afroamericano \\
\hline & Thamniobryum fasciculatum (Hedw.) Brid. & 0 & 2 & som & $\mathrm{D}$ & Neotropical \\
\hline Orthotrichaceae & Schlotheimia rugifolia (Hook.) Schwägr. & 6 & 0 & sol & $\mathrm{TP}$ & Neotrópico e Índia \\
\hline Phyllogoniaceae & Phyllogonium viride Brid. & 5 & 0 & som & $\mathrm{P}$ & Afroamericano \\
\hline
\end{tabular}


Tabela 2. Continuação...

\begin{tabular}{|c|c|c|c|c|c|c|}
\hline Família & Espécie & FR & TB & GE & FV & Padrão fitogeográfico \\
\hline \multirow[t]{9}{*}{ Pilotrichaceae } & Callicostella depressa (Hedw.) A. Jaeger & 0 & 1 & som & $\mathrm{TP}$ & Neotropical \\
\hline & Callicostella pallida (Hornsch.) Aongstr. & 2 & 9 & som & $\mathrm{TP}$ & Neotropical \\
\hline & Crossomitrium patrisiae (Brid.) Müll. Hal. & 1 & 10 & gen & $\mathrm{TP}$ & Neotropical \\
\hline & Cyclodictyon limbatum (Hampe) O. Kuntze & 0 & 4 & som & $\mathrm{TP}$ & Neotropical \\
\hline & Lepidopilidium brevisetum (Hampe) Broth. & 4 & 3 & som & $\mathrm{TP}$ & Floresta Atlântica \\
\hline & Lepidopilum muelleri (Hampe) Spruce & 0 & 3 & som & $\mathrm{F}$ & Neotropical \\
\hline & Lepidopilum surinamense Müll. Hal. & 0 & 4 & som & $\mathrm{F}$ & Neotropical \\
\hline & Pilotrichum evanescens (Müll. Hal.) Müll. Hal. & 1 & 3 & som & $\mathrm{D}$ & Neotropical \\
\hline & Thamniopsis incurva (Hornsch.) W.R. Buck & 1 & 5 & som & $\mathrm{TP}$ & Neotropical \\
\hline Pottiaceae & Leptodontium wallisii (Müll. Hal.) Kindb. & 1 & 0 & som & $\mathrm{TF}$ & Afroamericano \\
\hline Pterobryaceae & Jaegerina scariosa (Lorentz) Arzeni & 1 & 0 & gen & $\mathrm{TP}$ & Pantropical \\
\hline \multirow[t]{3}{*}{ Pylaisiadelphaceae } & Isopterygium subbrevisetum (Hampe) Broth. & 1 & 3 & gen & $\mathrm{TP}$ & Neotropical \\
\hline & Isopterygium tenerum (Sw.) Mitt. & 10 & 10 & gen & $\mathrm{TP}$ & Amplo \\
\hline & Taxithelium planum (Brid.) Mitt. & 0 & 7 & gen & $\mathrm{TP}$ & Pantropical \\
\hline Racopilaceae & Racopilum tomentosum (Hedw.) Brid. & 0 & 1 & som & $\mathrm{TP}$ & Amplo \\
\hline Rhizogoniaceae & Pyrrhobryum spiniforme (Hedw.) Mitt. & 1 & 0 & som & $\mathrm{TF}$ & Amplo \\
\hline \multirow[t]{5}{*}{ Sematophyllaceae } & Acroporium pulgens (Hedw.) Broth. & 5 & 0 & gen & $\mathrm{TP}$ & Neotropical \\
\hline & Sematophyllum subpinnatum (Brid.) E. Britton & 8 & 3 & gen & $\mathrm{TP}$ & Pantropical \\
\hline & Sematophyllum subsimplex (Hedw.) Mitt. & 7 & 1 & gen & $\mathrm{TP}$ & Neotropical \\
\hline & $\begin{array}{l}\text { Sematophyllum swartzii (Schwägr.) } \\
\text { W.H. Welch \& H.A. Crum }\end{array}$ & 3 & 1 & gen & $\mathrm{TP}$ & Neotropical \\
\hline & Trichosteleum papillosum (Hornsch.) A. Jaeger & 5 & 1 & gen & $\mathrm{TP}$ & Neotropical \\
\hline Thuidiaceae & Thuidium delicatulum (Hedw.) Bruch \& Schimp. & 0 & 2 & som & TR & Amplo \\
\hline \multicolumn{7}{|c|}{ Divisão Marchantiophyta } \\
\hline \multirow[t]{2}{*}{ Aneuraceae } & Riccardia digitiloba (Spruce ex Steph.)Pagán & 4 & 3 & gen & $\mathrm{TL}$ & Neotropical \\
\hline & Riccardia regnellii (Aongstr.) Hell & 0 & 1 & som & $\mathrm{TL}$ & Brasil \\
\hline \multirow[t]{2}{*}{ Calylogeiaceae } & Calypogeia lechleri (Steph.) Steph. & 3 & 6 & som & $\mathrm{TP}$ & Neotropical \\
\hline & Calypogeia peruviana Nees \& Mont. & 2 & 1 & som & $\mathrm{TP}$ & Neotropical \\
\hline Cephaloziaceae & Cephalozia crassifolia (Lindenb. \& Gottsche) Fulford & 0 & 1 & som & $\mathrm{TP}$ & Neotropical \\
\hline \multirow[t]{3}{*}{ Frullaniaceae } & Frullania brasiliensis Raddi & 0 & 1 & sol & $\mathrm{TP}$ & Neotropical \\
\hline & Frullania caulisequa (Nees) Nees & 4 & 1 & sol & $\mathrm{TP}$ & Neotropical \\
\hline & Frullania kunzei (Lehm. \& Lindenb.) Lehm. \& Lindenb. & 1 & 1 & sol & $\mathrm{TP}$ & Neotropical \\
\hline \multirow[t]{19}{*}{ Lejeuneaceae } & Acanthocoleus aberrans (Lindenb. \& Gottsche) Kruijt & 1 & 2 & sol & $\mathrm{TP}$ & Afroamericano \\
\hline & Anoplolejeunea conferta (Meissn.) A. Evans & 2 & 0 & gen & $\mathrm{TP}$ & Neotropical \\
\hline & Aphanolejeunea kunertiana Steph. & 1 & 1 & som & $\mathrm{TP}$ & Neotropical \\
\hline & Archilejeunea fuscescens (Hampe ex Lehm.) Fulford & 0 & 1 & gen & $\mathrm{TP}$ & Neotropical \\
\hline & Archilejeunea parviflora (Nees) Schiffn. & 0 & 3 & som & $\mathrm{TP}$ & Neotropical \\
\hline & Bryopteris diffusa (Sw.) Nees & 6 & 2 & som & $\mathrm{F}$ & Neotropical \\
\hline & Caudalejeunea lehmanniana (Gottsche) A. Evans & 3 & 4 & gen & TR & Afroamericano \\
\hline & Ceratolejeunea ceratantha (Nees \& Mont.) Steph. & 0 & 1 & gen & $\mathrm{TP}$ & Outro \\
\hline & Ceratolejeunea cornuta (Lindenb.) Schiffn. & 10 & 9 & gen & $\mathrm{TP}$ & Neotropical \\
\hline & Ceratolejeunea cubensis (Mont.) Schiffn. & 4 & 1 & gen & $\mathrm{TP}$ & Neotropical \\
\hline & Ceratolejeunea laetefusca (Austin) R.M. Schust. & 0 & 1 & gen & $\mathrm{TP}$ & Neotropical \\
\hline & Ceratolejeunea rubiginosa Gottsche ex Steph. & 2 & 0 & gen & $\mathrm{TP}$ & Neotropical \\
\hline & Cheilolejeunea acutangula (Nees) Grolle & 3 & 0 & gen & $\mathrm{TP}$ & Neotropical \\
\hline & Cheilolejeunea holostipa (Spruce) Grolle \& R.L. Zhu & 4 & 0 & gen & $\mathrm{TP}$ & Neotropical \\
\hline & Cheilolejeunea rigidula (Mont.) R.M. Schust. & 3 & 0 & gen & $\mathrm{TP}$ & Afroamericano \\
\hline & Cheilolejeunea trifaria (Reinw. et al.) Mizut & 10 & 4 & gen & $\mathrm{TP}$ & Pantropical \\
\hline & Cololejeunea cardiocarpa (Mont.) A. Evans & 1 & 0 & gen & $\mathrm{TP}$ & Pantropical \\
\hline & Cololejeunea obliqua (Nees \& Mont.) Schiffn. & 10 & 6 & gen & $\mathrm{TP}$ & Neotropical \\
\hline & Cololejeunea platyneura (Spruce) A. Evans & 0 & 1 & som & TP & Pantropical \\
\hline
\end{tabular}


Tabela 2. Continuação...

\begin{tabular}{|c|c|c|c|c|c|c|}
\hline Família & Espécie & FR & TB & GE & FV & Padrão fitogeográfico \\
\hline & Colura tortifolia (Nees \& Mont.) Steph. & 4 & 1 & sol & $\mathrm{TP}$ & Neotropical \\
\hline & Cyclolejeunea convextipa (Lehm. \& Lindenb.) A. Evans & 0 & 2 & som & $\mathrm{TP}$ & Neotropical \\
\hline & Cyclolejeunea luteola (Spruce) Grolle & 0 & 1 & som & $\mathrm{TP}$ & Neotropical \\
\hline & Diplasiolejeunea brunnea Steph. & 6 & 3 & sol & $\mathrm{TP}$ & Neotropical \\
\hline & Diplasiolejeunea cavifolia Steph. & 3 & 1 & sol & $\mathrm{TP}$ & Pantropical \\
\hline & Drepanolejeunea biocellata A. Evans & 0 & 1 & som & $\mathrm{TP}$ & Neotropical \\
\hline & Drepanolejeunea mosenii (Steph.) Bischl. & 7 & 1 & gen & $\mathrm{TP}$ & Neotropical \\
\hline & Harpalejeunea oxyphylla (Nees \& Mont.) Steph. & 5 & 0 & sol & $\mathrm{TP}$ & Neotropical \\
\hline & Harpalejeunea stricta (Lindenb. \& Gottsche) Steph. & 4 & 0 & sol & $\mathrm{TP}$ & Neotropical \\
\hline & Lejeunea cerina (Lehm. \& Lindenb.) Gottsche & 4 & 0 & gen & TR & Neotropical \\
\hline & Lejeunea controversa Gottsche & 6 & 9 & gen & $\mathrm{TP}$ & Neotropical \\
\hline & Lejeunea immersa Spruce & 0 & 5 & gen & $\mathrm{TP}$ & Neotropical \\
\hline & Lejeunea flava (Sw.) Nees & 10 & 4 & gen & $\mathrm{TP}$ & Pantropical \\
\hline & Lejeunea huctumalcensis & 1 & 4 & gen & $\mathrm{TP}$ & Neotropical \\
\hline & Lejeunea laetevirens Nees \& Mont. & 10 & 3 & sol & $\mathrm{TP}$ & Neotropical \\
\hline & Lejeunea magnoliae Lindenb. \& Gottsche & 4 & 0 & gen & $\mathrm{TP}$ & Neotropical \\
\hline & Lejeunea obtusangula Spruce & 0 & 2 & gen & $\mathrm{TP}$ & Neotropical \\
\hline & Lejeunea tapajosensis Spruce & 1 & 1 & gen & $\mathrm{TP}$ & Neotropical \\
\hline & Lepidolejeunea eluta (Nees) R.M. Schust. & 0 & 1 & sol & $\mathrm{TP}$ & Neotropical \\
\hline & Lepidolejeunea involuta (Gottsche) Grolle & 1 & 0 & som & $\mathrm{TP}$ & Neotropical \\
\hline & Leptolejeunea diversilobulata Bischl. & 1 & 0 & som & $\mathrm{TP}$ & Outro \\
\hline & Leptolejeunea elliptica (Lehm. \& Lindenb.) Schiffn. & 9 & 0 & sol & $\mathrm{TP}$ & Neotropical \\
\hline & $\begin{array}{l}\text { Leucolejeunea xanthocarpa (Lehm. \& Lindenb.) } \\
\text { A. Evans }\end{array}$ & 1 & 1 & sol & $\mathrm{TP}$ & Pantropical \\
\hline & Lopholejeunea nigricans (Lindenb.) Schiffn. & 4 & 4 & sol & $\mathrm{TP}$ & Pantropical \\
\hline & Lopholejeunea subfusca (Nees) Schiffn. & 4 & 1 & sol & $\mathrm{TP}$ & Pantropical \\
\hline & Marchesinia brachiata (Sw.) Schiffn. & 0 & 1 & sol & TR & Afroamericano \\
\hline & Metalejeunea cucullata (Reinw. et al.) Grolle & 1 & 0 & som & $\mathrm{TP}$ & Pantropical \\
\hline & Microlejeunea bullata (Tayl.) Steph. & 3 & 6 & gen & $\mathrm{TL}$ & Neotropical \\
\hline & Microlejeunea globosa (Spruce) Steph. & 2 & 0 & gen & $\mathrm{TP}$ & Neotropical \\
\hline & Odontolejeunea rhomalea (Spruce) Steph. & 0 & 1 & som & $\mathrm{TP}$ & Neotropical \\
\hline & Prionolejeunea aemula (Gottsche) A. Evans & 3 & 5 & som & $\mathrm{TP}$ & Neotropical \\
\hline & Stictolejeunea squamata (Willd. ex Weber) Schiffn. & 0 & 4 & gen & $\mathrm{TP}$ & Neotropical \\
\hline & $\begin{array}{l}\text { Symbiezidium barbiflorum (Lindenb. \& Gottsche) } \\
\text { A. Evans }\end{array}$ & 6 & 7 & gen & $\mathrm{TP}$ & Neotropical \\
\hline \multirow[t]{6}{*}{ Lepidoziaceae } & Bazzania aurescens Spruce & 3 & 0 & som & TR & Neotropical \\
\hline & Bazzania heterostipa (Steph.) Fulford & 10 & 6 & gen & TR & Floresta Atlântica \\
\hline & Bazzania phyllobola Spruce & 10 & 0 & som & TR & Outro \\
\hline & Kurzia capillaris (Sw.) Grolle & 1 & 0 & som & $\mathrm{TP}$ & Afroamericano \\
\hline & Monodactylopsis monodactyla (Spruce) R.M. Schust. & 2 & 0 & sol & $\mathrm{TP}$ & Neotropical \\
\hline & Telaranea diacantha (Mont.) Engel \& Merr. & 9 & 6 & gen & $\mathrm{TP}$ & Pantropical \\
\hline \multirow[t]{3}{*}{ Lophocoleaceae } & $\begin{array}{l}\text { Chyloscyphus martianus (Nees) } \\
\text { J.J. Engel \& R.M. Schust. }\end{array}$ & 5 & 10 & gen & $\mathrm{TP}$ & Afroamericano \\
\hline & $\begin{array}{l}\text { Chyloscyphus muricatus (Lehm.) } \\
\text { J.J.Engel \& R.M.Schust. }\end{array}$ & 0 & 7 & som & TR & Temperado do Sul \\
\hline & Lophocolea bidentata (L.) Dumort. & 0 & 3 & som & $\mathrm{TP}$ & Amplo \\
\hline \multirow[t]{4}{*}{ Metzgeriaceae } & Metzgeria albinea Spruce & 2 & 1 & gen & $\mathrm{TL}$ & Afroamericano \\
\hline & Metzgeria aurantiaca Steph. & 3 & 0 & gen & TL & Neotropical \\
\hline & Metzgeria brasiliensis Schiffn. & 0 & 10 & gen & $\mathrm{TL}$ & Floresta Atlântica \\
\hline & Metzgeria ciliata Raddi & 3 & 1 & gen & $\mathrm{TL}$ & Amplo \\
\hline Monocleaceae & Monoclea gottschei subsp. elongata Gradst. \& Mues & 0 & 1 & som & $\mathrm{TP}$ & Neotropical \\
\hline Pallaviciniaceae & Symphyogyna aspera Steph. & 0 & 3 & som & TL & Neotropical \\
\hline
\end{tabular}


Tabela 2. Continuação...

\begin{tabular}{|c|c|c|c|c|c|c|}
\hline Família & Espécie & FR & TB & GE & FV & Padrão fitogeográfico \\
\hline \multirow[t]{8}{*}{ Plagiochilaceae } & Plagiochila corrugata (Nees) Nees \& Mont. & 1 & 1 & som & $\mathrm{F}$ & Afroamericano \\
\hline & Plagiochila cristata (Sw.) Lindenb. & 1 & 0 & som & $\mathrm{F}$ & Neotropical \\
\hline & Plagiochila disticha (Lehm. \& Lindenb.) Lindenb. & 10 & 5 & som & $\mathrm{F}$ & Neotropical \\
\hline & $\begin{array}{l}\text { Plagiochila gymnocalycina (Lehm. \& Lindenb.) } \\
\text { Lindenb. }\end{array}$ & 0 & 1 & som & $\mathrm{F}$ & Neotropical \\
\hline & Plagiochila martiana (Nees) Lindenb. & 7 & 8 & som & $\mathrm{F}$ & Neotropical \\
\hline & Plagiochila patentissima Lindenb. & 7 & 6 & som & $\mathrm{F}$ & Neotropical \\
\hline & Plagiochila patula (Sw.) Lindenb. & 4 & 6 & som & $\mathrm{F}$ & Neotropical \\
\hline & Plagiochila rutilans Lindenb. & 4 & 6 & som & $\mathrm{F}$ & Neotropical \\
\hline Porellaceae & Porella brasiliensis (Raddi) Schiffn. & 0 & 1 & som & $\mathrm{TR}$ & Floresta Atlântica \\
\hline \multirow[t]{3}{*}{ Radulaceae } & Radula ligula Steph. & 0 & 9 & som & $\mathrm{TP}$ & Floresta Atlântica \\
\hline & Radula mammosa Spruce & 0 & 1 & som & $\mathrm{TP}$ & Neotropical \\
\hline & Radula recubans J. Taylor & 6 & 8 & gen & $\mathrm{TP}$ & $\begin{array}{c}\text { América tropical e } \\
\text { subtropical }\end{array}$ \\
\hline
\end{tabular}

Tabela 3. Índices de diversidade de espécies das comunidades de briófitas das florestas de Restinga e Terras Baixas, Ubatuba, SP, Brasil.

Table 3. Indices of species diversity of the bryophyte communities of the Restinga and Lowland Forests, Ubatuba, SP, Brazil.

\begin{tabular}{lcc}
\hline \multicolumn{1}{c}{$\begin{array}{c}\text { Índice de } \\
\text { diversidade }\end{array}$} & $\begin{array}{c}\text { Floresta } \\
\text { de } \\
\text { Restinga }\end{array}$ & $\begin{array}{c}\text { Floresta } \\
\text { de Terras } \\
\text { Baixas }\end{array}$ \\
\hline Diversidade de espécies (= riqueza) & 109 & 112 \\
Índice de Simpson & 0,986 & 0,985 \\
Índice de Shannon & 4,444 & 4,409 \\
Número efetivo de espécies (Simpson) & 71 & 67 \\
Número efetivo de espécies (Shannon) & 85 & 82 \\
Diversidade taxonômica (IDT) & 5,133 & 5,33 \\
Intervalo de confiança IDT - limite superior & 5,29 & 5,305 \\
Intervalo de confiança IDT - limite inferior & 5,183 & 5,16 \\
\hline
\end{tabular}

de Terras Baixas de Poço das Antas (município de Miguel Pereira, Rio de Janeiro), agrupou-se com baixa similaridade florística.

\section{Padrões fitogeográficos $\times$ altitude}

Nas duas fitofisionomias amostradas, a maioria das espécies apresenta uma ampla distribuição no mundo, sendo mais de 55\% delas neotropicais. Táxons neotropicais somados àqueles com padrões de distribuição mais amplos (América tropical e subtropical, afroamericano, pantropical e amplo), daqui em diante denominados amplamente distribuídos, totalizaram 103 táxons em ambas as fitofisionomias (94\% dos táxons da FR e 92\% daqueles de TB), resultados semelhantes aos encontrados por Imbassahy et al. (2009), para a Restinga de Jurubatiba, no Estado do Rio de Janeiro (90\% dos táxons). Para uma área submontana na Serra dos Órgãos (Santos \& Costa 2008), o número de espécies de briófitas amplamente distribuídas diminui (81\%) e essa tendência também foi observada para a flora de hepáticas do Rio de Janeiro (Santos \& Costa 2010b), com $84 \%$ dos táxons de terras baixas, $78 \%$ de submontana, $74 \%$ de montana e $64 \%$ de alto-montana, quanto para a flora de musgos (Costa \& Lima 2005), com $85,90,74$ e $65 \%$, respectivamente.

\section{Discussão}

\section{Estrutura das comunidades de briófitas das florestas de Restinga e Terras Baixas}

A análise da brioflora das duas fitofisionomias amostradas revelou uma elevada riqueza de espécies de briófitas, apesar da pequena área inventariada (20 subparcelas de $10 \times 10 \mathrm{~m}$ dentro de dois hectares). Nessas áreas, foram encontradas $43 \%$ das espécies, $58 \%$ dos gêneros e $69 \%$ das famílias conhecidas para o litoral norte do Estado de São Paulo (Visnadi 2005). Ao comparar a riqueza de espécies de cada uma dessas fitofisionomias separadamente com a de outros inventários realizados na Floresta Atlântica do sudeste brasileiro (Tabela 1), verifica-se que o número de espécies de ambas as áreas é inferior apenas ao da floresta submontana da RPPN El Nagual, onde foi realizado o levantamento intensivo da brioflora numa área de 17 ha (Santos \& Costa 2008).

A riqueza de espécies foi semelhante nas duas áreas, tendo sido ligeiramente maior em TB (112 táxons), possivelmente devido à sua elevada heterogeneidade ambiental, visto que esta fitofisionomia apresenta maior disponibilidade de microambientes para as briófitas (e.g. rochas no interior da mata, córregos e barrancos - ambientes não encontrados na FR), o que está diretamente relacionado com a riqueza de espécies. São exemplos de plantas que crescem exclusivamente sobre rocha, encontradas apenas em TB, Megaceros vincentianus, Monoclea gottschei, Riccardia regnellii e Symphyogyna aspera. A riqueza também expressiva da FR (109 espécies) pode ser atribuída à sua singularidade fitofisionômica, que apresenta elevada luminosidade e períodos de alagamento durante a estação chuvosa, apresentando ainda uma umidade atmosférica possivelmente elevada, devido ao número considerável de espécies de briófitas epífilas (que crescem sobre folhas) encontradas (10 espécies). Por tratar-se de um ambiente tão singular, essa fitofisionomia apresenta espécies típicas de restingas (por exemplo, Cololejeunea cardiocarpa e Monodactylopsis monodactyla) e de florestas ombrófilas, como Aerolindgia capillacea, Meteoridium remotifolium, Phyllogonium viride, Squamidium spp. e Zelometeorium patulum.

A composição florística possibilitou uma distinção efetiva entre as fitofisionomias de FR e TB de Picinguaba, como corroborado pela análise de agrupamento (Figura 3). Foram encontradas diferenças na brioflora dessas áreas até mesmo em nível de família e gênero. 


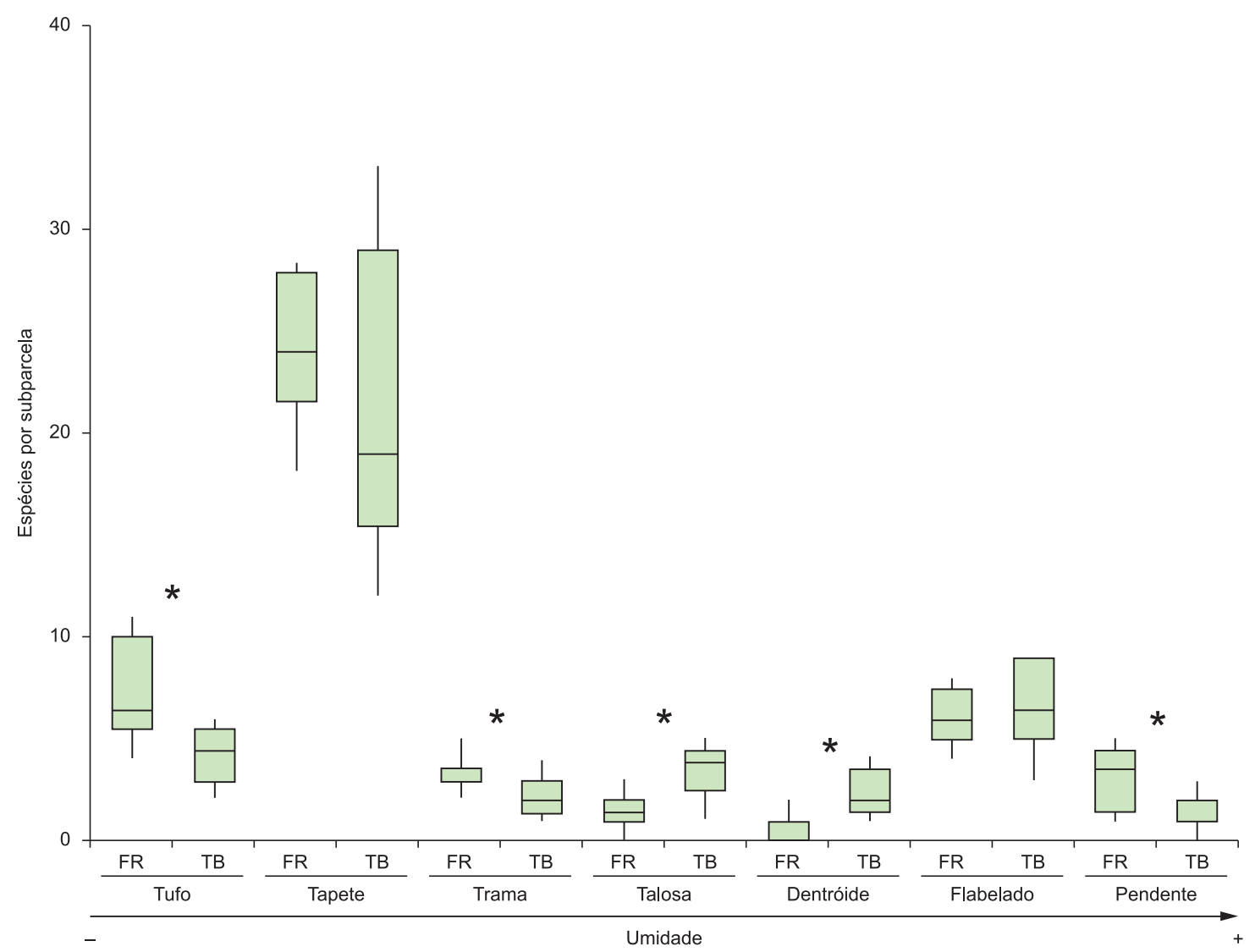

Figura 1. Box-plot do número de espécies por tipo de forma de vida das 10 subparcelas da Floresta de Restinga e 10 subparcelas de Terras Baixas, Ubatuba, SP, Brasil. * denota diferença significativa entre os valores das duas fitofisionomias $(\mathrm{p}<0,05)$. Siglas: FR = Floresta de Restinga, TB = Floresta Ombrófila Densa de Terras Baixas.

Figure 1. Box-plot of the number of species per life form of 10 plots from the Forest of Restinga and 10 plots of Lowland Forest, Ubatuba, SP, Brazil. * Denotes significant difference between the values of the two forest types $(\mathrm{p}<0.05)$. Abbreviations: $\mathrm{FR}=$ Restinga Forest, $\mathrm{TB}=$ Lowland Forest.

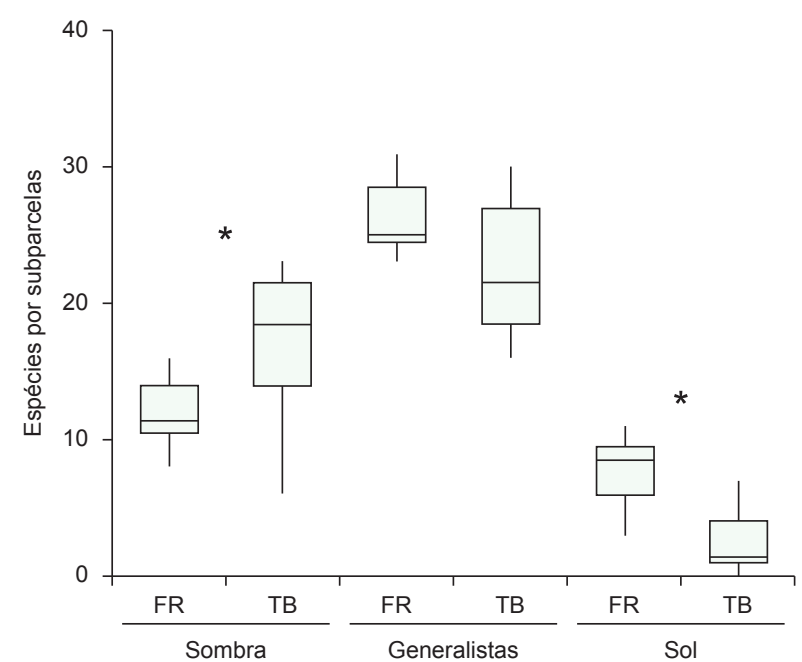

Figura 2. Box-plot do número de espécies por grupo ecológico de tolerância à luz das 10 subparcelas da Floresta de Restinga e 10 subparcelas de Terras Baixas, Ubatuba, SP, Brasil. * Denota diferença significativa entre os valores das duas fitofisionomias $(\mathrm{p}<0,05)$. Siglas: $F R=$ Floresta de Restinga, $\mathrm{TB}=$ Floresta Ombrófila Densa de Terras Baixas.

Figure 2. Box-plot of the number of species per ecological group of light tolerance of 10 plots from the Forest of Restinga and 10 plots of Lowland Forest, Ubatuba, SP, Brazil. * Denotes significant difference between the values of the two forest types $(\mathrm{p}<0.05)$. Abbreviations: $F R=$ Restinga Forest, $\mathrm{TB}=$ Lowland Forest.
Dentre os principais táxons da FR, destacam-se membros da família Brachytheciaceae (com três espécies e um gênero exclusivos) e Lepidoziaceae (quatro espécies e dois gêneros exclusivos). $\mathrm{Na}$ floresta de TB, famílias destacáveis como Pilotrichaceae (quatro espécies e dois gêneros exclusivos) e Neckeraceae (duas espécies e dois gêneros exclusivos) apresentaram espécies típicas de sombra que crescem principalmente sobre rochas ou troncos caídos, encontradas exclusivamente nesta fitofisionomia. Houve ainda um número elevado de famílias exclusivas de cada área. Segundo dados da lista do Brasil (Costa 2010), dentre as 10 famílias exclusivas à TB, quatro (Daltoniaceae, Dendrocerotaceae, Hypopterygiaceae e Monocleaceae) são encontradas no Brasil exclusivamente em domínios florestais (Amazônia e Floresta Atlântica), enquanto que as famílias exclusivas da FR estão amplamente distribuídas no país (exceto Phyllogoniaceae, restrita à Floresta Atlântica), ocorrendo inclusive em biomas secos (e.g. Orthotrichaceae, Pottiaceae e Pterobryaceae, que ocorrem em todos os domínios fitogeográficos brasileiros).

Foram encontradas divergências entre os índices de diversidade utilizados (Tabela 3). Em termos de riqueza de espécies (desconsiderando a equabilidade) e de diversidade taxonômica, a fitofisionomia de TB foi considerada mais diversa. Já para os índices de diversidade que levam em consideração a riqueza e equabilidade (Simpson e Shannon), a maior diversidade foi encontrada na FR (inclusive em termos de número efetivo de táxons). Na FR, o número de espécies raras (que ocorreram em apenas uma subparcela) foi menor (28 táxons vs. 41 em TB) e a distribuição das abundâncias mais 


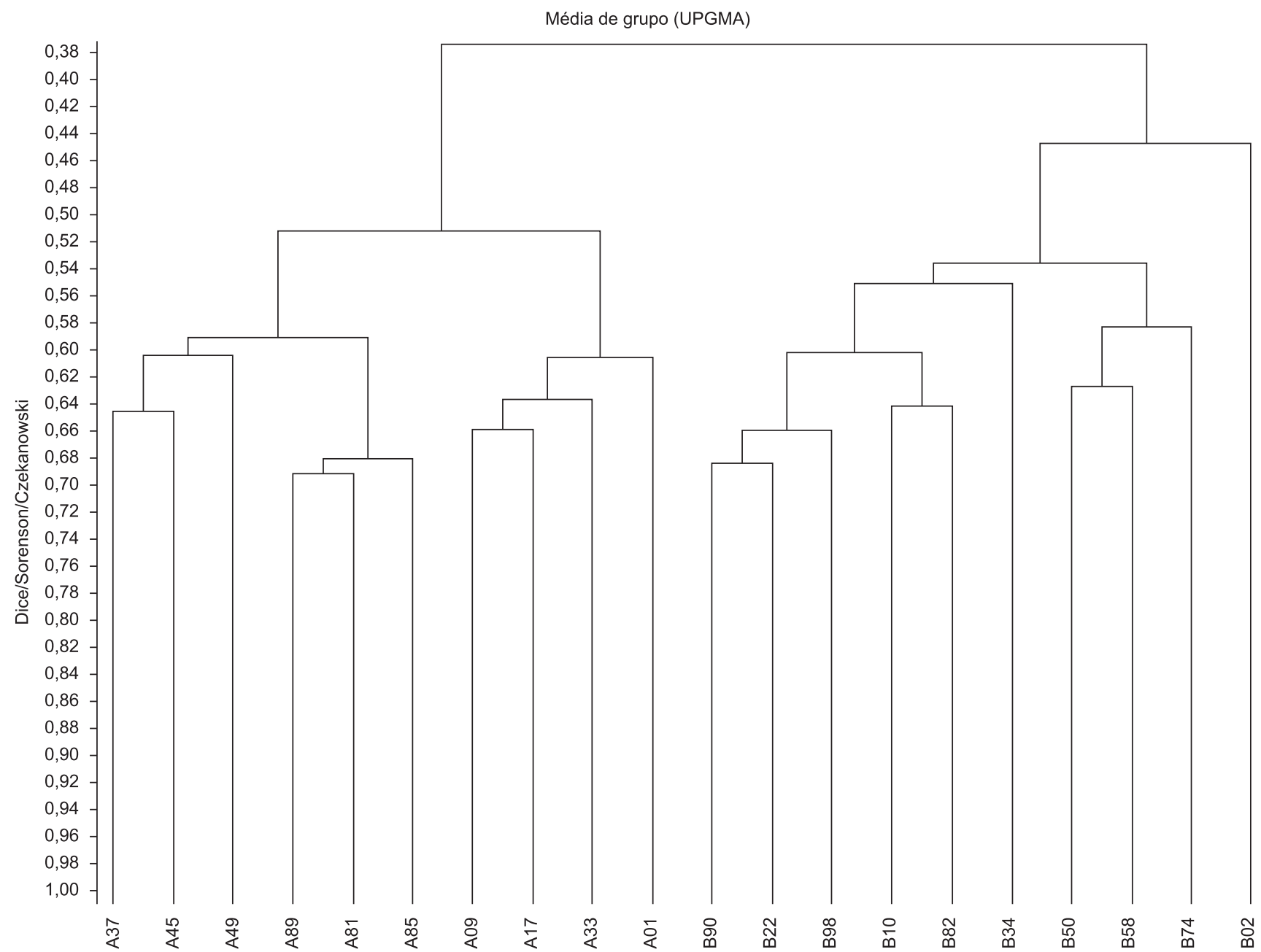

Figura 3. Dendograma de similaridade (coeficiente de Sørensen) obtido pelo do método de ligação de Média de Grupo (UPGMA) a partir da matriz florística das 20 subparcelas inventariadas nas florestas de Restinga e Terras Baixas, Ubatuba, SP, Brasil.

Figure 3. Similarity tree (Sørensen's coefficient) obtained by cluster analysis (UPGMA) from the floristic matrix of 20 subplots surveyed in the in the Restinga and Lowland forests, Ubatuba, SP, Brazil.

equitativa entre as subparcelas; já na parcela de TB a heterogeneidade ambiental é maior, como observado na Figura 4, havendo algumas subparcelas com elevado número de microambientes colonizados por briófitas e outras, localizadas em terreno inclinado, onde a representatividade das espécies foi menor. Os métodos de estimativa da diversidade têm sido amplamente discutidos na literatura (ver Martins \& Santos 1999, Magurran 2004, Melo 2008, Jost 2006). Um dos problemas frequentemente apontados é a forma de interpretação dos índices, já que eles não representam a diversidade de espécies em si, sendo o valor do índice, algo abstrato e de difícil entendimento (Jost 2006, Melo 2008). Neste trabalho, optou-se pela utilização do número efetivo de espécies, um índice menos popular, pois ele permite a comparação de duas comunidades de forma mais clara, quantificando a diversidade em número de táxons (Jost 2006). Com relação à diversidade taxonômica, uma de suas virtudes é a robustez com relação ao esforço amostral (Magurran 2004). Além disso, em termos de conservação da biodiversidade, uma área com elevada diversidade taxonômica deveria ser priorizada, visto abrigar um número maior de linhagens evolutivas dentro da comunidade. Do ponto de vista da diversidade taxonômica, apesar da diferença entre os índices não ter sido significativa, a floresta de TB seria considerada prioritária para conservação, pois nela são encontrados representantes das três divisões de "briófitas", sendo ainda maior o número de famílias e gêneros.

Foram encontradas diferenças significativas nos parâmetros tipos de forma de vida e grupo ecológico de tolerância à luz entre as fitofisionomias (Figuras 1 e 2). Na FR, foram encontradas mais espécies com forma de vida do tipo tufo (17 táxons na FR e 11 em $\mathrm{TB}$ ) e pendente (nove na FR e quatro em TB); enquanto que em TB, destacaram-se as espécies talosas (oito táxons e cinco na FR) e dendróides (seis táxons e dois na FR). Formas de vida de briófitas estão intimamente relacionadas com as condições de luminosidade e umidade, visto que representam o arranjo do tecido fotossintético de forma a maximinizar a produção primária e minimizar a perda d'água por evaporação (Bates 1998). Logo, espécies pendentes e flabeladas, que apresentam grande parte dos gametófitos expostos ao ar para uma maior captura de luz e água da chuva, são típicas de florestas tropicais úmidas. Ambientes tropicais com elevada umidade do ar, em geral apresentam muitas espécies pendentes, flabeladas, dendróides e talosas, enquanto que aqueles de baixa umidade apresentam tufos e coxins (Giminghan \& Birse 1957). Dessa forma, o número mais expressivo de espécies que formam tufos e daquelas pendentes reitera as condições climáticas singulares da FR. Por outro lado, o maior número de táxons talosos (e.g. Megaceros vincentianus, 


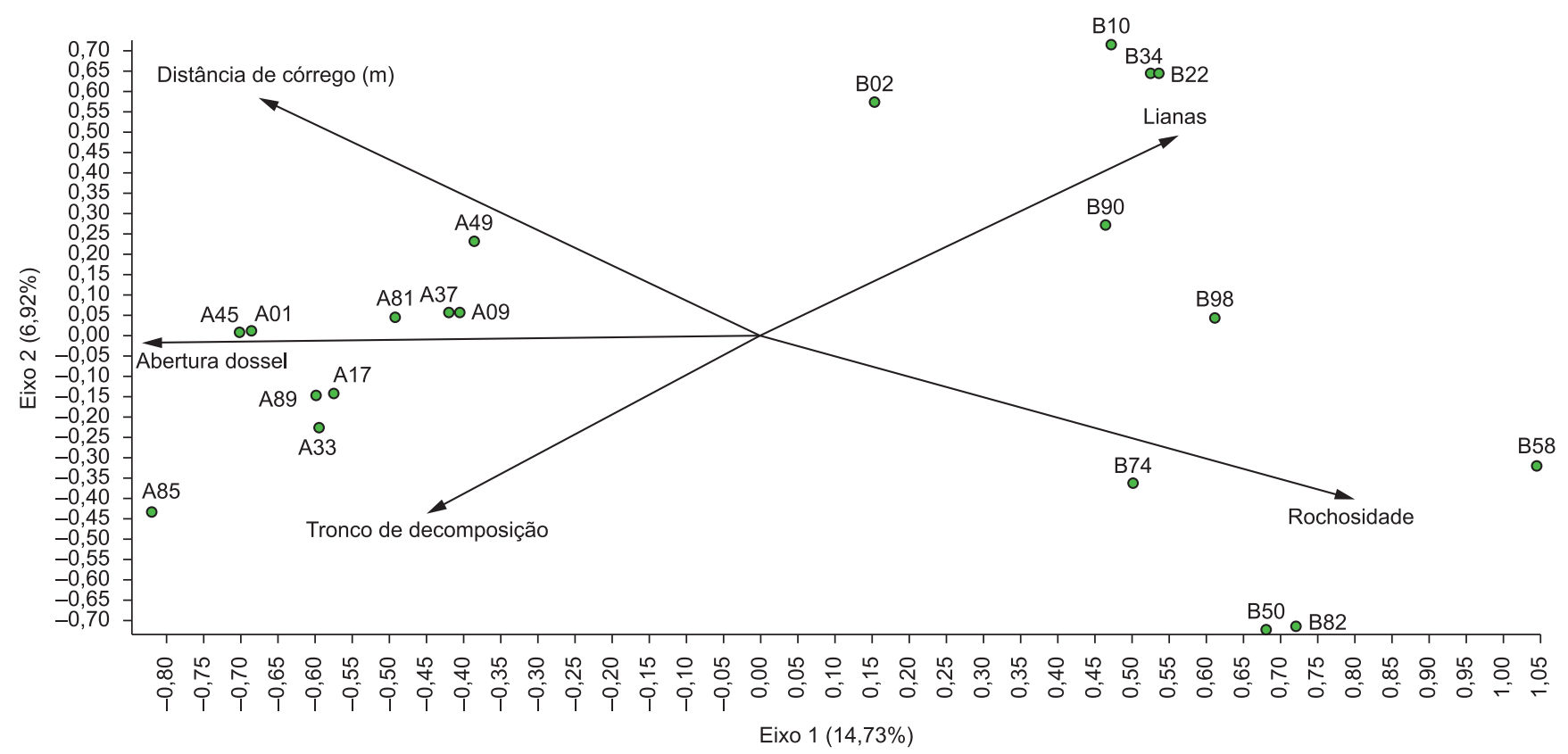

Figura 4. Diagrama de ordenação dos dois primeiros eixos da Análise de Correspondência Canônica (CCA) para as 20 subparcelas inventariadas nas florestas de Restinga e Terras Baixas, Ubatuba, SP, Brasil.

Figure 4. Ordination diagram of the first two axes of Canonical Correspondence Analysis (CCA) for the 20 subplots surveyed in the Restinga and Lowland forests, Ubatuba, SP, Brazil.

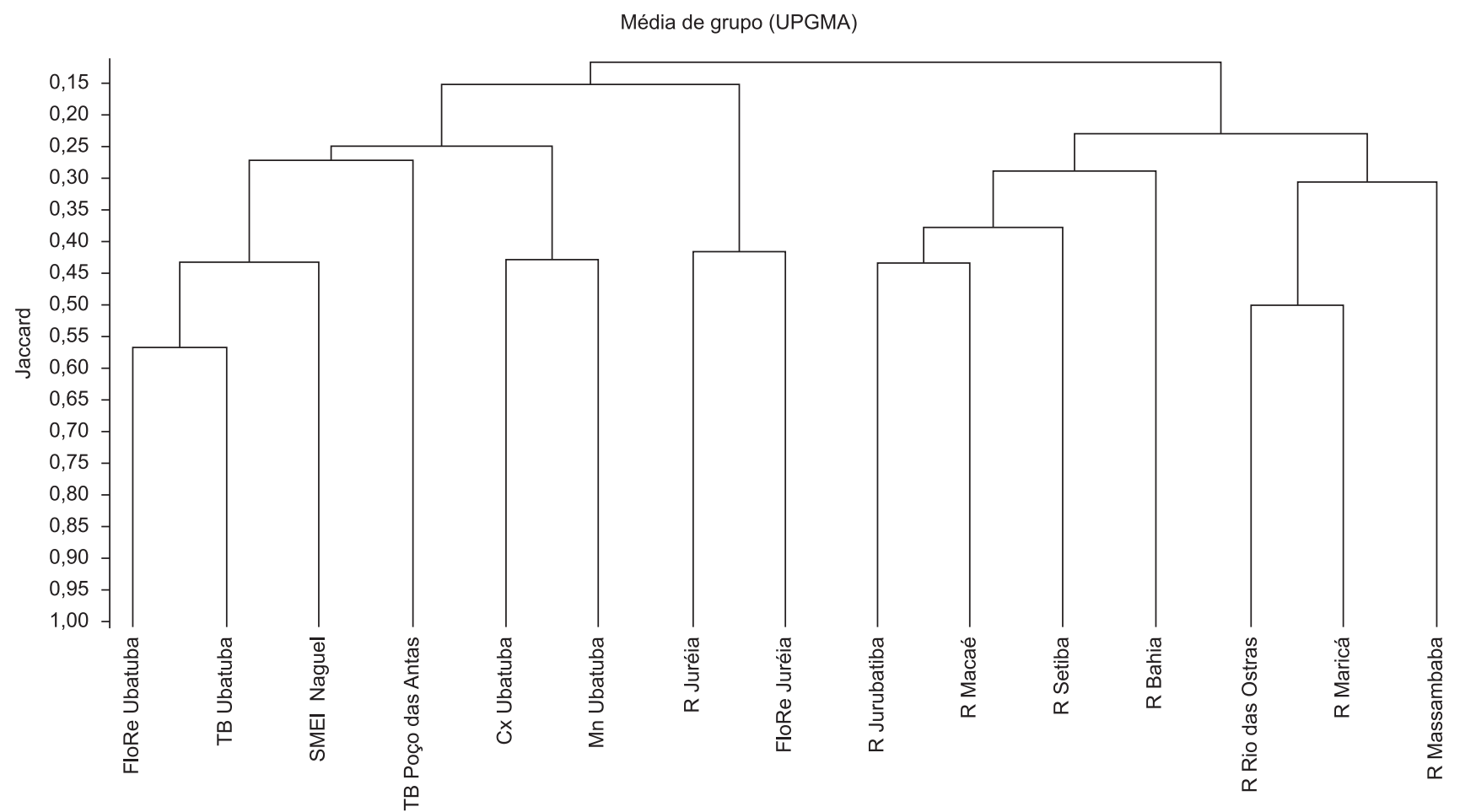

Figura 5. Dendograma de similaridade (coeficiente de Jaccard) obtido a partir do método de ligação de Média de Grupo (UPGMA) a partir da lista florística sem espécies raras de 15 áreas de Floresta Atlântica costeira. As siglas são apresentadas na Tabela 1.

Figure 5. Similarity tree (Jaccard's coefficient) obtained by cluster analysis (UPGMA) from the floristic list excluding rare species of the 15 areas of coastal Atlantic Forest. For definition of acronym see Table 1. 
Monoclea gottschei, Symphyogyna aspera) e dendróides (e.g. Hypopterygium tamarisci, Thamniobryum fasciculatum) em TB, estão relacionados a duas características ambientais desta fitofisionomia, a menor abertura do dossel (visto que os táxons que apresentaram esses tipos de formas de vida são típicos de sombra) e a disponibilidade de rochas, substrato preferencialmente ocupado por essas espécies.

Em se tratando da tolerância à luz (dessecação), a riqueza de espécies típicas de sol foi maior na FR e de típicas de sombra em TB. O índice de abertura do dossel explicou $44 \%$ da variação da riqueza de espécies típicas de sol nas 20 subparcelas inventariadas. Provavelmente, outras variáveis ambientais, e.g. umidade, também estão atuando na distribuição desses táxons tolerantes à elevada luminosidade. A abertura do dossel faz com que as condições microclimáticas (de luminosidade, temperatura e umidade) existentes na copa das árvores cheguem até o sub-bosque, possibilitando assim a ocorrência de espécies típicas de sol no interior da floresta, ambiente preferencialmente ocupado pelas espécies típicas de sombra (Acebey et al. 2003).

\section{Distinção florística entre Floresta de Restinga $\times$ FOD de Terras Baixas em termos de paisagem}

A baixa similaridade florística existente entre as subparcelas da FR e TB demonstram que a FR de Picinguaba é uma formação ímpar e distinta da floresta ombrófila da encosta da Serra do Mar. A CCA possibilitou a visualização do padrão de variação da composição das comunidades de briófitas ao longo dos gradientes gerados pelas variáveis ambientais analisadas, apesar dos três primeiros eixos compreenderem apenas ca. $25 \%$ da variância total dos dados. A variância remanescente não explicada pode estar associada a variáveis ambientais não quantificadas, como umidade, inclinação do terreno, dentre outras. Assim sendo, a maior abertura do dossel, aliada à ausência de córregos e elevada quantidade de troncos em decomposição são variáveis ambientais que explicam parcialmente a distribuição da brioflora nas subparcelas da FR. Por outro lado, a elevada rochosidade pode ser considerada explicativa do grupo formado pelas subparcelas B50, B58 e B74 na análise de agrupamento (Figura 3). Da mesma forma, a baixa similaridade existente entre a subparcela B02 e as outras amostras de TB pode estar relacionada com suas características ambientais intermediárias entre as fitofisionomias FR e TB.

\section{Singularidade da Floresta de Restinga em nível regional}

Quando avaliadas em termos de paisagem, as subparcelas da FR e TB formam grupos florísticos distintos, com baixo grau de similaridade; contudo, na análise regional, a brioflora dessas duas fitofisionomias apresenta mais afinidades entre si do que com outras formações litorâneas de Floresta Atlântica, como observado na Figura 5. No agrupamento observado, é interessante notar que as duas florestas de terras baixas (TB Poço das Antas e TB Ubatuba) não se agruparam (30\% de similaridade florística), isso devido provavelmente à REBIO Poço das Antas ser uma área de Floresta Atlântica de baixada com florestas em diferentes estágios sucessionais, enquanto que a TB Ubatuba representa uma área de Floresta Atlântica de encosta em bom estado de conservação, e que por isso agrupou-se com a FR de Ubatuba (57\%) e a RPPN El Nagual (48\%), uma área de floresta submontana localizada no sopé da Serra dos Órgãos (200 m). A baixa similaridade existente entre a FR de Ubatuba e a FR da Juréia (10\%), ambas localizadas no litoral de São Paulo, indica que provavelmente as formações vegetacionais do litoral sul do Estado de São Paulo são distintas daquelas do litoral norte, que são mais semelhantes aos remanescentes de Floresta Atlântica fluminenses. Contudo, estudos mais detalhados são necessários para compreender melhor essa dissimilaridade. É importante destacar que a brioflora da FR de Ubatuba apresenta maiores afinidades com aquela de áreas de florestas ombrófilas de encosta do que com a de outras formações vegetacionais mais próximas ao litoral (como caxetal, mangue e restinga), o que reforça a singularidade dessa fitofisionomia.

\section{Relações entre os padrões de distribuição globais e regionais das briófitas}

Com relação aos padrões fitogeográficos, corroboramos as observações de Santos \& Costa (2010b) para a Floresta Atlântica do sudeste do Brasil, de que as espécies de briófitas de áreas de baixada são mais amplamente distribuídas em termos globais do que aquelas das florestas montanas. Como destacado por Schuster (1983) e Gradstein \& Pócs (1989), nas regiões tropicais, as razões de endemismo de briófitas são maiores em áreas montanas, sendo os elementos de terras baixas em geral amplamente distribuídos. Regiões montanas são como ilhas bióticas, visto que as espécies que vivem ali ocupam áreas pequenas e com populações restritas, que estão sujeitas ao stress, deriva genética e rápida evolução, acentuada pelas flutuações climáticas do Pleistoceno (Schuster 1983). Além disso, as condições microclimáticas existentes em áreas de baixada (menores índices de umidade e maiores temperaturas) podem restringir o estabelecimento dos esporos das espécies de distribuição restrita (e.g. endêmicas). Evidências experimentais demonstraram que os esporos de briófitas endêmicas são menos tolerantes às condições necessárias para dispersão a longa distância (e.g. dessecação e raios UV) do que de espécies com distribuição transoceânica (van Zanten \& Pócs 1981).

Os resultados obtidos corroboram a proposição de que a FR de Picinguaba (Ubatuba) é uma formação vegetacional ímpar, já que sua brioflora apresenta elementos de florestas ombrófilas (e.g. forma de vida pendente, espécies epífilas e táxons típicos de sombra) entremeados aos de vegetações secas (e.g. formas de vida tapete e tufo, táxons típicos de sol), resultados confirmados nas análises de afinidades florísticas em nível de paisagem. Demonstram ainda que, em nível regional, a composição florística desta fitofisionomia é mais semelhante àquela das florestas de encosta do que a de outras formações litorâneas brasileiras. Dessa forma, seria mais adequado enquadrá-la como uma subformação da fitofisionomia florestal do que como uma variação da fitofisionomia de restinga. Além disso, foi reforçada a idéia de que as espécies de briófitas que ocorrem em áreas de baixada apresentam padrões fitogeográficos mais amplos do que aquelas de áreas montanas.

\section{Agradecimentos}

Os autores agradecem à Thamara J. Reis, pelo auxílio na identificação dos táxons; à Christiane E. Corrêa, Dalila V. Freitas, Rafael C. Costa e Valéria Forni-Martins por terem cedido os dados de abertura do dossel; e à Adaíses S. Maciel da Silva, Ana Gabriela Bieber, Bruno P. Rosado e Leonardo D. Meireles, pelo auxílio nas análises estatísticas. Este trabalho foi financiado pela Fundação de Amparo à Pesquisa do Estado de São Paulo (FAPESP) no âmbito do Projeto Temático Gradiente Funcional (Processo 03/12595-7), que faz parte do Programa BIOTA/FAPESP - O Instituto Virtual da Biodiversidade (www.biota.org.br). Autorização COTEC/IF 260108001.482/0 2008.

\section{Referências bibliográficas}

ACEBEY, C., GRADSTEIN, S.R. \& KRÖMER, T. 2003. Species richness and habitat diversification of bryophytes in submontane rain forest and fallows in Bolivia. J. Trop. Ecol. 18:1-16. 
ALVARENGA, L.D.P., PÔRTO, K.C. \& OLIVEIRA, J.R.P.M. 2010 Habitat loss effects on spatial distribution of non-vascular epiphytes in a Brazilian Atlantic Forest. Biodivers. Conserv. 19:619-635. http://dx.doi. org/10.1007/s10531-009-9723-2

AYRES, M., AYRES JÚNIOR, M., AYRES, D.L. \& SANTOS, A.A. 2007. BIOESTAT - Aplicações estatísticas nas áreas das ciências biológicas e médicas. Ong Mamiraua, Belém.

BASTOS, C.J.P. 1999. Briófitas de restinga das regiões metropolitana de Salvador e litoral norte do Estado da Bahia, Brasil. Dissertação de Mestrado, Instituto de Biociências da Universidade de São Paulo, São Paulo.

BASTOS, C.J.P. \& YANO, O. 2006. Briófitas de restinga das regiões Metropolitana de Salvador e Litoral Norte do Estado da Bahia, Brasil. Bolm. Inst. Bot. 18:197-205

BATES, J.W. 1998. Is 'life-form' a useful concept in bryophyte ecology? Oikos 82:223-237. http://dx.doi.org/10.2307/3546962

BEHAR, L., YANO, O. \& VALLANDRO, C.G. 1992. Briófitas da restinga de Setiba, Guarapari, Espírito Santo. Bol. Mus. Biol. Mello Leitão, Nov. Ser., 1:25-38.

BUCK, W.R. 1998. Pleurocarpous mosses of the West Indies. Mem. New York Bot. Gard. 82:1-400

CABRERA, A.L. \& WILLINK, A. 1980. Biogeografia de America Latina. $2^{\text {nd }}$ ed. OEA, Washington.

CLARKE, K.R. \& WARWICK, R.M. 1998. A taxonomic distinctness index and its statistical properties. J. Appl. Ecol. 35(4):523-531. http://dx.doi. org/10.1046/j.1365-2664.1998.3540523.x

COSTA, D.P. 1999. Epiphytic bryophyte diversity in primary and secondary Lowland Rainforests in southeastern Brazil. Bryologist 102(2): 320-326.

COSTA, D.P. 2008. Metzgeriaceae. Fl. Neotr. Monograph. 102:1-169.

COSTA, D.P. 2009. Briófitas. In Plantas da Floresta Atlântica (J.R. Stehmann, R.C. Forzza, A. Salino, L.M. Sobral, D.P. Costa \& L.H.Y. Kamino, eds.). Jardim Botânico do Rio de Janeiro, Rio de Janeiro, p.13-17.

COSTA, D.P. 2010. Briófitas: Lista de Espécies da Flora do Brasil. Jardim Botânico do Rio de Janeiro. http://floradobrasil.jbrj.gov.br/2010/ FB000006 (último acesso em 30/nov/2010).

COSTA, D.P. \& LIMA, F.M. 2005. Moss diversity in the tropical rainforest of Rio de Janeiro, Southeastern Brazil. Rev. Bras. Bot. 28:671-685. http://dx.doi.org/10.1590/S0100-84042005000400003

COSTA, D.P., IMBASSAHY, C.A.A., ALMEIDA, J.S.S., SANTOS, N.D. \& VAZ-IMBASSAHY, T.F. 2006. Diversidade das briófitas nas Restingas do Estado do Rio de Janeiro, Brasil. Bol. Inst. Bot. 18:131-139.

CRANDALL-STOTLER, B., STOTLER, R.E. \& LONG, D.G. 2009 Morphology and classification of the Marchantiophyta. In Bryophyte Biology. ${ }^{\text {nd }}$ ed. (B. Goffinet \& A.J. Shaw, eds.). Cambridge University Press, p.1-54.

DAUPHIN, G. 2003. Ceratolejeunea (Lejeuneaceae: Lejeuneoideae). Fl. Neotr. Monograph 90:1-86.

FOURNIER, L.A. 1974. Un método cuantitativo para la medición de características fenológicas en árboles. Turrialba 24:422-423.

FRAHM, J-P. \& GRADSTEIN, S.R. 1991. An altitudinal zonation of tropical rain forests using bryophytes. J. Biog. 18:669-678. http://dx.doi. org/10.2307/2845548

FRAZER, G.W., CANHAM, C.D., \& LERTZMAN, K.P. 1999. Gap Light Analyzer (GLA): Imaging software to extract canopy structure and gap light transmission indices from true-colour fisheye photographs, users manual and program documentation. Simon Fraser University, Burnaby, British Columbia, and the Institute of Ecosystem Studies, Millbrook, New York.

GIMINGHAN, C.H. \& BIRSE, E.M. 1957. Ecological studiesw on growth form in bryophytes I. Correlation between growth form and habitat. J. Ecol. 45:533-545. http://dx.doi.org/10.2307/2256934

GOFFINET, B. \& SHAW, A.J. 2009. Bryophyte Biology. $2^{\text {nd }}$ ed. Cambridge University Press.
GOFFINET, B., BUCK, W.R. \& SHAW, A.J. 2009. Morphology and classification of the Bryophyta. In Bryophyte Biology. (B. Goffinet \& A.J. Shaw, eds.). $2^{\text {nd }}$ ed. Cambridge University Press, p.55-138.

GRADSTEIN, S.R. \& PÓCS, T. 1989. Bryophytes. In Tropical rain forest ecosystems (H. Lieth \& M. J. A. Werger, eds.). Elsevier, Amsterdam, p.311-325.

GRADSTEIN, S.R. \& COSTA, D.P. 2003. The Hepaticae and Anthocerotae of Brazil. Mem. New York Bot. Gard. 87:1-336.

GRADSTEIN S.R., CHURCHILL, S.P. \& SALAZAR-ALLEN, N. 2001. Guide to the bryophytes of tropical America. Mem. New York Bot. Gard. 86:1-577.

HALLINGBÄCK, T. \& HODGETTS, N. 2000. Mosses, liverworts \& hornworts: a status survey and conservation action plan for bryophytes. IUCN, Gland.

HAMMER, O., HARPER, D.A.T. \& RYAN, P.D. 2001. PAST: Paleontological Statistics software package for education and data analysis. Palaentol. Electronica 4(1):9.

HEINRICHS, J., GRADSTEIN, S.R. \& GROLLE, R. 1988. A revision of the neotropical species of Plagiochila (Dumort.) Dumort. (Hepaticae) described by Olof Swartz. Journ. Hattori Bot. Lab. 85:1-32. http://dx.doi. org/10.1007/BF00985374

HEINRICHS, J., ANTON, H., GRADSTEIN, S.R. \& MUES, R. 2000. Systematics of Plagiochila sect. Glaucescentes Carl (Hepaticae) from Tropical America: a morphological and chemotaxonomical approach. Pl. Syst. Evol. 220:115-138.

IMBASSAHY, C.A.A.I., COSTA, D.P. \& ARAUJO, D.S.D. 2009. Briófitas do Parque Nacional da Restinga de Jurubatiba, RJ, Brasil. Acta bot. bras. 23(2): 558-570.

JOLY, C.A., ASSIS, M.A., BERNACCI, L.C., CAMPOS, M.C.R., GOMES, J.A.M.A., LACERDA, M.S., MARTINS, F.R., PEDRONI, F., PEREIRA, L.S., PADGURSCHI, M.C., PRATA, E.M.B., RAMOS, E., ROCHELE, A., TAMASHIRO, J.Y., TORRES, R.B., ALVES, L.F., VIEIRA, S.A., SIMÕES, E., VILLANI, J.P. \& MARTINELLI, L.A. 2011. Florística e fitossociologia da Mata Atlântica do sudeste do Brasil ao longo de um gradiente altitudinal.

JOLY, C.A. \& MARTINELLI, L.A. 2004. Projeto Composição florística, estrutura e funcionamento da Floresta Ombrófila Densa nos Núcleos Picinguaba e Santa Virgínia do Parque Estadual da Serra do Mar. FAPESP 03/12595-7.

JOST, L. 2006. Entropy and diversity. Oikos 113:363-374. http://dx.doi. org/10.1111/j.2006.0030-1299.14714.x

MÄGDEFRAU, K. 1982. Life forms of bryophytes. In Bryophyte Ecology (A.J.E. Smith ed.). New York, p.45-58.

MAGURRAN, A.E. 2004. Measuring biological diversity. Blackwell, Malden.

MARTINS, F.R. \& SANTOS, F.A.M. 1999. Técnicas usuais de estimativa da biodiversidade. Rev. Holos 1 (edição especial):236-267.

McCUNE, B.\& MEFFORD, M.J. 1999. PC-ORD: multivariate analysis of ecological data, version 4.10. MjM Sofware Design, Gleneden Beach.

MELO, A.S. 2008. O que ganhamos 'confundindo' riqueza de espécies e equabilidade em um índice de diversidade? Biota Neotrop. 8(3): http://www.biotaneotropica.org.br/v8n3/pt/abstract?point-ofview+bn00108032008 (último acesso 28/nov/2010).

PERALTA, F.P. 1995. Musgos (Bryophyta) do Parque Estadual da Ilha Anchieta (PEIA), São Paulo, Brasil. Dissertação de mestrado, Instituto de Botânica, São Paulo.

PÓCS, T. 1982. Tropical Forest Bryophytes. In Bryophyte Ecology (A.J.E. Smith, ed.). Chapman and Hall, London, New York, p.59-103.PÓCS, T. 1996. Epiphyllous liverwort diversity at worldwide level and its threat and conservation. Anales Inst. Biol. Univ. Nac. Autón. México, Ser. Bot. 67(1):109-127.

REESE, W.D. 1993. Calymperaceae. Fl. Neotr. Monograph 58:1-102.

REINER-DREHWALD, M.E. 2000. Las Lejeuneaceae (Hepaticae) de Misiones, Argentina. VI Lejeunea y Taxilejeunea. Trop. Bryol. 19:81-131. 
REINER-DREHWALD, M.E. \& GODA, A. 2000. Revision of the genus Crossotolejeunea (Lejeuneaceae, Hepaticae). Journ. Hattori Bot. Lab. 89:1-54.

RENZAGLIA, K.S., VILLAREAL, J.C. \& DUFF, R.J. 2009. New insights into morphology, anatomy, and systematic of hornworts. In Bryophyte Biology (B. Goffinet \& A.J. Shaw, eds.). $2^{\text {nd }}$ ed. Cambridge University Press, p.139-171.

RICHARDS, P.W. 1984. The Ecology of Tropical Forest Bryophytes. In New Manual of Bryology (R.M. Schuster, ed.). The Hattori Botanical Laboratory, Nichina, Japan, p.1233-1270.

SANTOS, N.D. \& COSTA, D.P. 2008. A importância de Reservas Particulares do Patrimônio Natural para a conservação da brioflora da Mata Atlântica: um estudo em El Nagual, Magé, RJ, Brasil. Acta Bot. Bras. 22(2):359-372. http://dx.doi.org/10.1590/S0102-33062008000200007

SANTOS, N.D. \& COSTA, D.P. 2010a. Altitudinal zonation of liverworts in the Atlantic Forest, Southeastern Brazil. Bryologist 113(3):631-645. http://dx.doi.org/10.1639/0007-2745-113.3.631

SANTOS, N.D. \& COSTA, D.P. 2010b. Phytogeography of the liverwort flora of the Atlantic Forest of southeastern Brazil. J. Bryol. 32:9-22. http://dx.doi.org/10.1179/037366810X12578498135634

SCHUSTER, R.M. 1983. Phytogeography of bryophytes. In New Manual of Bryophtes (R.M. Schuster ed.). Hattori Botanical Laboratory, Nichinan, p.463-626.

SHEPHERD, G.J. 2009. Fitopac v. 2.0. Universidade Estadual de Campinas, Campinas.

SILVA, M.P.P. \& PÔRTO, K.C. 2010. Spatial structure of bryophyte communities along na edge-interior gradient in na Atlantic Forest remmant in Northeast Brazil. J. Bryol. 32:101-112. http://dx.doi.org/10 $.1179 / 037366810 \mathrm{X} 12578498136110$

TER BRAAK, C.J.F. \& PRENTICE, I.C. 1988. A theory of gradient analysis. Adv. Ecol. Res. 18:271-313. http://dx.doi.org/10.1016/S00652504(08)60183-X

VALENTIN, J.L. 2000. Ecologia Numérica: Uma introdução à análise multivariada de dados ecológicos. Interciência, Rio de Janeiro, 117p.

van ZANTEN, B.O. \& PÓCS, T. 1981. Distribution and dispersal of Bryophytes. Adv. Bryol. 1:479-562.
VAZ, T.F. \& COSTA, D.P. 2006a. Os gêneros Brymella, Calliscotella, Crossomitrium, Cyclodictyon, Hookeriopsis, Hypnella e Trachyxiphium (Pilotrichaceae, Bryophyta) no Estado do Rio de Janeiro, Brasil. Acta Bot. Bras. 20:955-973. http://dx.doi.org/10.1590/S0102-33062006000400019

VAZ, T.F. \& COSTA, D.P. 2006b. Os gêneros Lepidopilidium, Lepidopilum, Pilotrichum e Thamniopsis (Pilotrichaceae, Bryophyta) no Estado do Rio de Janeiro, Brasil. Acta Bot. Bras. 20:975-993. http://dx.doi.org/10.1590/ S0102-33062006000400020

VAZ-IMBASSAHY, T.F., IMBASSAHY, C.A.A. \& COSTA, D.P. 2008. Sinopse de Pilotrichaceae (Bryophyta) no Brasil. Rodriguésia 59:765-797.

VELOSO, H.P., RANGEL FILHO, A.L.R. \& LIMA, J.C.A. 1991. Classificação da Vegetação Brasileira adaptada a um Sistema Universal. IBGE, Rio de Janeiro.

VISNADI, S.R. 2005. Brioflora da Mata Atlântica do Estado de São Paulo: região norte. Hoehnea 32(2):215-231.

VISNADI, S.R. 2008. Marchantiophyta e Bryophyta de manguezais do Estado de São Paulo, Brasil. Bol. Mus. Para. Emílio Goeldi. Ser. Cienc. Nat. 3(1):69-80.

VISNADI, S.R. 2009. Briófitas do caxetal, em Ubatuba, São Paulo, Brasil. Trop. Bryol. 30:8-14.

VISNADI, S.R. \& VITAL, D.M. 1995. Bryophytes from restinga in Setiba State Park, Espírito Santo State, Brazil. Trop. Bryol.10:69-74.

VITAL, D.M. \& VISNADI, S.R. 1994. Briófitas de um trecho de restinga da Estação Ecológica da Juréia, Peruíbe, Estado de São Paulo, Brasil. Anais do III Simpósio de Ecossistemas da Costa Brasileira. ACIESP, v. 87 , n. 3 , p. 153-157.

YANO, O. 1984. Briófitas. In Técnicas de coleta, preservação e herborização de material botânico (O. Fidalgo \& V.L.R. Bononi, coords.). Instituto de Botânica, São Paulo, p.27-30.

WARWICK, R.M. \& CLARKE, K.R. 1995 New 'biodiversity' measures reveal a decrease in taxonomic distinctness with increasing stress. Mar. Ecol. Prog. Ser. 129:301-305. http://dx.doi.org/10.3354/meps129301

ZARTMAN, C.E. 2003. Habitat Fragmentation Impacts on Epiphyllous Bryophyte Communities in Central Amazonia. Ecology 84 (4):949-954. http://dx.doi.org/10.1890/0012-9658(2003)084[0948:HFIOEB]2.0.CO;2

Recebido em 09/09/2010 Versão reformulada recebida em 30/04/2011 Publicado em 06/06/2011 